\title{
A Theory of Trade Policy under Dictatorship and Democratization ${ }^{1}$
}

\author{
Ben Zissimos ${ }^{2}$ \\ University of Exeter
}

September 5th, 2017

\begin{abstract}
This paper develops a new model of trade policy under dictatorship and democratization. The paper makes two contributions. One is to provide a deeper understanding of the relationship between political institutions and economic efficiency by studying the endogenous interaction between the form of government and trade policy. The paper's second contribution is to show how a dictatorship can manipulate trade policy to maintain its grip on power in the face of permanent world price shocks, thus opening the door to a re-examination of trade policy responses to technology shocks. The model is used to explain an interesting episode of trade policymaking between 1815 and 1846, during which time Britain substantially liberalized trade while Prussia, on the other side of the grain market, significantly increased protectionism.
\end{abstract}

Keywords. Commitment problem, efficiency, fiscal capacity, institutions, trade policy.

JeL Classification Numbers: D30, D74, F11, F13, P16.

\footnotetext{
${ }^{1}$ Special thanks are due to an editor, two anonymous referees, Rick Bond, Kaustav Das, Kishore Gawande, Peter Jensen, Ron Jones, Christos Kotsogiannis, Elena Seghezza, Jeff Williamson and Isleide Zissimos for detailed comments on earlier drafts. For other useful comments and conversations about this paper I am grateful to numerous colleagues, and seminar participants at Duisburg, FIU, Loughborough, LSE, Maryland, Nottingham, Rochester, Ryerson, SMU, UCD, a Silvaplana Workshop, the 1st InsTED Workshop, Exeter, the Midwest International Economics Meetings, Michigan, and the ABCDE conference at the World Bank. I am also grateful to Vanderbilt University for their hospitality while I was working on part of this project.

${ }^{2}$ Dept of Economics, University of Exeter Business School, Exeter, EX4 4ST, UK.

Tel: ++44 1392726466 .

E-mail: b.zissimos@exeter.ac.uk
} 


\section{Introduction}

Classical scholars recommend that democratization and trade liberalization go hand in hand on efficiency grounds. Building on the point that international trade is efficiency enhancing, Smith (1776) argues that democracy helps to support harmonious international economic relations, of which free international trade is a central pillar. However, more recent work in political science has argued that democracy may also empower distributional coalitions with intense protectionist interests, making higher levels of protectionism more likely (Rogowski 1989, Garrett 2000: 973). Both possibilities have found support in empirical research (O'Rourke and Taylor 2007, Decker and Lim 2009, Aidt and Gassebner 2010). Yet to the best of my knowledge there is no wellaccepted theoretical framework or set of basic results on the relationship between the form of government (dictatorship or democracy), trade policy, and economic efficiency. ${ }^{3}$

This paper's first contribution is to provide such a framework and to analyze its main implications. Using this framework, we will be able to show that it is only when a ruling elite own a relatively scarce factor that democratization can be expected to go hand in hand with trade liberalization and an increase in economic efficiency. When the elite own a relatively abundant factor, the advice of classical scholars will go unheeded in that democratization will be accompanied by an increase in protectionism. Hence the paper presents a clear testable prediction as to when democratization can be expected to result in an increase, and when it may actually result in a decrease, of economic efficiency through resultant changes in trade policy. A third possibility revealed by the framework is that the ruling elite may be able to use trade policy to forestall democratization.

The paper's second contribution, made possible by the new framework developed, is to examine the trade-policy responses by dictatorial regimes to price shocks. Throughout history the advent of price shocks, especially food price shocks, has been one of the main triggers of unrest provoking challenges to dictatorships. ${ }^{4}$ Yet price shocks cannot be analyzed in most of the models that endogenize the form of government since these tend to be based on singlesector macro models and so have been overlooked in the prior literature. Since our model has

\footnotetext{
${ }^{3}$ In their path-breaking work, Acemoglu and Robinson (2006) do present a model of globalization and trade liberalization which offers important insights into some aspects of this relationship (see Chapter 10). But, since globalization is exogenous in their model, they do not consider the choice by government over trade policy and they do not consider the economic efficiency implications.

${ }^{4}$ See Williamson (2012) for a review of the literature showing that commodity price volatility can adversely affect economic performance and provoke political instability.
} 
the underlying structure of an international trade model with two sectors, price shocks can be analyzed in a natural way. Given that price shocks can be triggered by technology shocks, the implication of technology shocks for political stability can and will be analyzed as well. ${ }^{5}$

The model that we will develop combines Mayer's (1984) $2 \times 2$ Heckscher-Ohlin (H-O) model of international trade and trade policy with Acemoglu and Robinson's (2000) model of the form of government (henceforth AR). The AR framework is extended to provide a new motivation for trade policy. But the AR framework, being a single-sector model, cannot be used to consider economic efficiency while the international trade policy framework features clear efficiency implications. Thus, the combination of these two models extends each in a non-trivial way to provide a new political-economy model of trade policy-making, which yields new insights that would not be available from either of the original models on their own.

The underlying economic model is of a country at a relatively early stage of development. Accordingly, there are two productive factors: labor and land. There are two groups within society: the elite and the rest of society. The term 'elite' is used to represent an old regime elite such as a landed aristocracy. The 'rest of society' encompasses the working class and possibly an emerging industrial middle class. In the stylized setting of a two-factor two-good model, we will assume that both groups own labor but only the elite own land. This is a reasonable assumption for a less developed country, where factor ownership tends to be highly polarized and factor markets poorly functioning. Since the underlying production structure is given by the H-O model, the standard results of new classical trade theory apply. As predicted by the Stolper-Samuelson theorem, the owners of the abundant factor prefer a relatively open trade regime while the owners of the scarce factor prefer a regime that is more protectionist. We will consider situations where land is the abundant factor and the scarce factor respectively.

In seeking to isolate the relationship between the form of government, trade policy, and economic efficiency in the face of price shocks, we will assume that a trade tax is the only policy instrument available. This assumption has firm foundations in the data in two respects. First, countries at an early stage of development tend not to invest in domestic fiscal capacity. As Besley and Persson (2011: 41-43) state: "Arguably, trade taxes and income taxes are two

\footnotetext{
${ }^{5}$ The framework introduced in this paper focuses on a situation where world price shocks are permanent, which seems reasonable when the underlying forces driving the shocks are permanent such as technological innovation. The model could be extended to consider other situations where world price shocks are temporary, such as crop failures arising from extreme weather events. We will discuss this possibility in the concluding section.
} 
polar opposite cases. To collect trade taxes requires being able to observe trade flows at major shipping ports. Although such tax allocations may encourage smuggling, it is a much easier proposition than collecting income taxes. The latter requires major investments in enforcement and compliance structures throughout the economy. ... High-income countries tend to depend more on income taxes, whereas middle- and, in particular low-income countries depend more on trade taxes." The second reason is that, to the extent that domestic fiscal capacity is installed, it tends not to be used for progressively redistributive purposes until after extension of the franchise. Aidt and Jensen (2009) show this in the data for a sample of ten Western European countries covering the period 1860-1938. Since our focus is on a country at the relatively early stages of development, that has not yet extended the franchise, it seems reasonable to assume in our stylized characterization that there is no domestic fiscal capacity and that only trade taxes are available. ${ }^{6}$

Reviewing the paper's first contribution, it shows how trade policy can be used to resolve a commitment problem that the elite face under the threat of revolution. AR argue that the elite's purpose in extending the voting franchise is to resolve a commitment problem that they face under the threat of revolution. The commitment problem arises if the elite cannot make sufficiently large transfers, within a single period, to compensate the rest of society for the gains that they would enjoy from a revolution. If transfers must be made over multiple periods, and if the threat of revolution may dissipate prior to the transfers being completed, then the elite will not be able to credibly commit to transfers large enough to defuse the threat of revolution. By extending the franchise, the elite transfer power to set taxes to the rest of society, and thus democratization makes a credible commitment to sufficiently large transfers. Domestic lumpsum redistributive taxation is the policy instrument used in AR's framework. But the literature cited above argues that domestic fiscal capacity did not exist for such redistribution prior to extension of the franchise. The present paper identifies the circumstances under which trade taxes, the capacity for which did exist prior to extension of the franchise, could be used to make such redistributions and hence resolve the commitment problem.

Since the elite would always prefer to retain power (including the power to set trade taxes) rather than extend the franchise, the paper also provides a way to think about when the elite can

\footnotetext{
${ }^{6}$ Prior to extension of the franchise, in addition to trade taxes, other types of taxation such as excise taxes were used to fund public good provision, especially defense. But, unlike trade taxes, excise taxes tend not to imply progressive redistribution so we will leave them aside as well.
} 
use trade policy to forestall democratization. As an alternative to extending the franchise, the elite may be able to neutralize the threat of revolution and forestall democratization by making temporary concessions to the rest of society over trade policy, thus using trade policy to maintain their grip on power. We will refer to the price level arising from a trade policy concession that is implemented to defuse a revolutionary threat and maintain the political status quo as the 'status quo price'. From our framework we will be able to delineate precisely where the elite face a commitment problem and hence must extend the franchise, and where they do not face a commitment problem and hence can use trade policy to forestall democratization.

Characterization of equilibrium lies at the heart of the paper's first contribution. This determines the conditions when the elite have to extend the franchise in order to defuse a revolutionary threat or alternatively when they can forestall democratization by adopting the status quo price. It also determines when trade liberalization goes hand in hand with democratization and when democratization will be accompanied by an increase in protectionism. If the rest of society own the relatively abundant factor then, since the median voter is a member of the rest of society, democratization will be accompanied by trade liberalization. However, if they own the relatively scarce factor then democratization will be accompanied by an increase in protectionism. If the elite can use trade policy to forestall democratization, then we will find that the status quo price concedes greater openness if the rest of society own the abundant factor and greater protection if they own the scarce factor. It may be implemented by import tariffs and/or export taxes that lie between autarky and free trade.

As mentioned above, this paper provides a framework in which the efficiency implications of democratization can be examined. If the rest of society own the relatively abundant factor and democratization is accompanied by trade liberalization then democratization will involve an increase in economic efficiency. It is when the rest of society own the relatively scarce factor that democratization will lead to an increase in protection and a reduction in economic efficiency. The main insight from this aspect of the analysis is that any consideration of the efficiency implications of democratization must take comparative advantage and factor ownership into account. This insight may be useful in framing future empirical investigations.

Placing the paper's first contribution, the majority of the previous literature on institutions and economic efficiency has focused on the role not of political but of economic institutions in the determination of economic performance. Following North (1981), the main focus of 
attention has been on economic institutions that define and enforce contracts and property rights, although the regulation of entry, financial markets, technology and fiscal capacity are also regarded as important (La Porta, Lopez-de-Silanes, Shleifer and Vishny, e.g. 1997, Acemoglu, Johnson and Robinson, e.g. 2001, Rodrik, e.g. 2007, Besley and Persson e.g. 2011). This 'macroeconomic institutions literature' has shown that countries with better rule of law and more private property rights have on average grown faster, where faster growth is associated with better allocative efficiency. At the same time, Besley and Jayaraman (2010) point out that “... there is clearly a great deal of heterogeneity in institutions as well as in outcomes associated with a given institutional metric." The literature on the interaction between economic institutions and international trade provides some insight into how such heterogeneity can arise. It does so by arguing that poor institutions can be a source of rent for some groups while institutions can also be a source of comparative advantage. Consequently, the welfare consequences arising from the interaction between economic institutions and international trade are shown to be ambiguous (Engerman and Sokoloff 1997, Levchenko 2007, 2013, Nunn 2007, Costinot 2009). The present paper, by focusing on the interaction between political institutions and economic efficiency, shows how there can be a heterogeneity of efficiency outcomes associated with the institution of democracy. Furthermore it shows that this heterogeneity depends systematically on the endogenous interaction between comparative advantage and underlying factor ownership.

Turning to the paper's second contribution, in examining trade-policy responses by dictatorial regimes to price shocks, our framework opens the door to a deeper understanding of how trade policy evolved during an interesting episode of history. The episode concerns the evolution of British trade policy during the period from the end of the Napoleonic Wars in 1815 to the eventual repeal of the Corn Laws in 1846. A great deal of research has focused on Britain's repeal of the Corn Laws in 1846, when tariffs of 7 percent were repealed to free trade. The framework developed in this paper additionally makes it possible to understand the prior period from 1815 until just before repeal (as well as repeal itself), during which tariffs were reduced from 70 percent to 7 percent. The explanation I propose is grounded in the fact that Britain's ruling elite owned land, used intensively to produce agriculture, while the country had a comparative advantage in manufactures which at that time were labor intensive. So the elite preferred a relatively closed regime, and at the end of the Napoleonic Wars put in place the Corn Laws to protect the income they made from land. During the 1800s there was a transport revolution that dramatically reduced the world prices of grain for importers such as Britain (O'Rourke 
and Williamson 1999: 33-36). The fall in prices made revolution more appealing to the rest of society in Britain since if they were able to depose the elite regime they would adopt more open trade policy, facilitating access to cheap grain from the world market. This in turn mandated a gradual fall in the status quo price, which the elite brought about through trade liberalization. ${ }^{7}$

This account would not be complete without considering the other side of the grain market, which was dominated by Prussia. Prussia's aristocracy, like Britain's, held their wealth in large estates. But, differently from Britain, Prussia had a comparative advantage in agricultural products such as grain which Britain imported. As owners of the abundant factor, Prussia's elite enacted low tariffs after the end of the Napoleonic wars, again differently from Britain. But as transport costs fell and world prices of grain rose, benefitting exporters but putting import-competing industries under pressure, the Prussian ruling elite came under pressure to raise protectionism and did so steadily between 1815 and 1846 (Kindleberger 1975). The most dramatic rise in protectionism came in 1847 when harvests failed throughout Europe and grain prices rose sharply. In the face of 'hunger riots' in Prussia, export taxes on grain were raised by 25 percent in an attempt to keep domestic grain prices from rising and thereby maintain the status quo, as would be predicted by our model (Solar 1997). ${ }^{8}$

Placing the paper's second contribution, most of the prior literature on trade policy focuses on a stable institutional environment where democracy has already been consolidated. In that literature, interest groups are able to lobby the government in order to try to influence the

\footnotetext{
${ }^{7}$ It may seem counterfactual to think of Britain as a dictatorship of the elite in the mid 19th Century when it already had a democratically elected chamber in the Houses of Parliament called the House of Commons. Indeed, much of the past literature on repeal of the Corn Laws focuses on lobbying by industrialists of the House of Commons in classic Grossman-Helpman fashion. However, recent work by Schonhardt-Bailey draws attention to the fact that at that time the unelected House of Lords, whose peers consisted of the landed aristocracy, held veto power over any policy passed by the House of Commons. This in turn meant that the tension that drove repeal was not so much between the industrialists and the House of Commons but more between the ordinary people who threatened revolution and the House of Lords who would lose political and economic power if a revolution occurred (Schonhardt-Bailey 2006: 2, 227). Research on British democratization prior to Schonhardt-Bailey has attributed major significance to Britain's Representation of the People Act of 1832. While certainly an important advance in the process of British democratization, in that it gave a greater number of seats in the House of Commons to constituencies from northern industrial cities such as Manchester, Schonhardt-Bailey argues that the really decisive step in Britain's democratization was taken when the Lords' veto was removed in the Representation of the People Act of 1867. This view is endorsed by recent research in history; see for example Farrell (2010). Further evidence in support of this view is presented in Appendix B.

${ }^{8}$ The 19th Century trade policy experiences of Britain and Prussia have not, to my knowledge, been linked previously in general political-economic equilibrium. The forces driving policy in these two countries are identified by the seminal work of Rogowski (1989). He invokes the logic of the Stolper-Samuelson theorem to argue (nonformally but drawing on a broad range of historical accounts) that the owners of abundant factors are likely to organize politically and push for trade liberalization while owners of scarce factors are likely to resist it, possibly resulting in the threat of a revolution. Unlike in the present paper he considers Britain and Prussia separately, and does not link trade policy evolution in the two countries to changes in transport costs.
} 
electoral outcome, or sway policy in the direction they would like to see it go (Hillman 1982, Hillman and Ursprung 1988, Grossman and Helpman 1994, Bagwell and Staiger 1999). Relating to a different branch of that literature, the use of democratization in our model to commit to a certain trade policy is similar to the commitment rationale for trade agreements espoused by Maggi and Rodriguez-Clare (1998). When the institutional environment in practice is closer to that characterized in the present paper, our model may be able to explain patterns in the data that are more difficult to explain using standard political economy models. Consider the decline in transport costs in the first half of the nineteenth century described above, that lead to a decrease in protectionism in Britain but an increase in Prussia. In a Grossman-Helpman model one would expect both countries to respond in the same way (either by increasing or reducing protection) under the assumption of symmetrical political structures across countries, where the government responded to organized interests in import-competing sectors. The difference with the model developed in this paper is that it provides an explanation of the different British and Prussian reactions within a common model of the political constraints faced by governments. ${ }^{9}$ More generally, our approach opens the door to a consideration of how governments motivated by a desire to preserve their power may respond differently to common technology shocks based on their differing underlying fundamentals.

This paper complements a third branch of the literature that examines how political institutions are determined by strategic interaction between elite groups and the rest of society (Lizzeri and Persico 2004, Llavador and Oxoby 2005, Jack and Lagunoff 2006). Most closely related to ours, Galiani and Torrens (2014) consider a framework where, in the face of the threat of a revolution, power can be shifted to the elite group whose interests are most aligned with those of workers. To defuse the threat of revolution, the elite can thus make a credible commitment to adopt the trade policy stance that workers prefer, but maintain income tax policy at a level that the elite would prefer. In all the papers of this third branch of the literature, political institutions and policy changes are determined through a shift in the balance of power between elite groups. By assuming only two groups, an elite and the rest of society, the present paper deliberately abstracts from intra-elite interactions. It focuses instead on partial shifts in

\footnotetext{
${ }^{9}$ This paper also provides a new explanation for how trade policy can fluctuate over time. Bagwell and Staiger $(1990,2003)$ model fluctuations in the level of protection over time but these arise as a result of temporary surges in import demand, or variations in total demand over the business cycle. In the present paper, trade policy fluctuations come about through endogenous changes in the weights on the government's objective function. The incorporation of temporary import demand fluctuations into the framework of the present paper is a promising area of future research that will be discussed further in the concluding section.
} 
trade policy in an attempt to forestall democratization. The papers in this third branch of the literature cannot account for such partial shifts in trade policy because they do not have the capacity to account for the trade policy revenue considerations. This capacity enables us to examine incremental changes in trade policy over time, and is necessary to be able to carry out comparative statics on trade policy and hence analyze world price shocks. ${ }^{10}$

The paper is structured as follows. Section 2 develops the economic model based around the $\mathrm{H}-\mathrm{O}$ model and uses this to characterize the levels of protectionism that would be preferred by the elite and the rest of society respectively. Equilibrium is characterized in Section 3, using the economic model of Section 2 to determine the payoffs in a dynamic game, through which the form of government and trade policy are determined. Section 4 examines the effects of a permanent world price shock on trade policy. Section 5 discusses these effects in the light of the episodes of 19th Century trade policy-making in Britain and Prussia introduced above. Conclusions are drawn in Section 6. Proofs of results are presented in Appendix A where indicated; other proofs are in the main text. Appendix B presents longer discussions of trade policy in Britain and Prussia in the early 19th Century and provides further evidence of the fit of these episodes to the analytical framework. The appendices are available online.

\section{The H-O Model with Trade Policy}

The model is of a single small country, populated by a continuum of risk-neutral agents. Each agent is placed in one of two groups: the elite, $\varepsilon$, or 'the rest of society,' $\rho$. The mass of each of these groups is normalized to $\theta$ and 1 respectively so that the total mass of the population is $1+\theta$. The elite constitutes a minority of the population: $\theta<1$.

The model has an infinite time horizon. A subscript- $t$ denotes the time period $t=0,1, \ldots, \infty$. The economy is endowed with two primary factors. One of these factors is labor, $l$, the endowment $1+\theta$ of which is equally shared across the elite and the rest of society. For concreteness we will refer to the other factor as land, $\lambda$, although this could equally be capital, the endowment $\theta$ of which is distributed evenly but solely among members of the elite. Let $y_{t}^{j}$ denote agent $j$ 's

\footnotetext{
${ }^{10}$ The present paper is also related to two others. Liu and Ornelas (2014) study the relationship between participation in free trade agreements and the sustainability of democracy. Their model shows that free trade agreements can critically reduce the incentive of authoritarian groups to seek power by destroying protectionist rents, thus increasing the chances of democratic consolidation. Garfinkel, Skaperdas and Syropoulos' (2008) work is also related in that it considers the relationship between trade policy and political institutions, where their focus is on the possibility of conflict over a traded resource that can lead to civil war.
} 
factor income in period $t, j \in\{\varepsilon, \rho\}$. Then a member of the elite's factor income is given by $y_{t}^{\varepsilon}=w_{t}+r_{t}$, while a member of the rest of society's factor income is $y_{t}^{\rho}=w_{t}$, where $r_{t}$ and $w_{t}$ are the rental rate and wage in period $t$ respectively. We will be interested in how aggregate income is divided between the two groups as a result of changes in trade policy. So it will be useful to know the factor income share $\phi_{t}^{j}$ for a member of each group:

$$
\phi_{t}^{j}=y_{t}^{j} / y_{t}
$$

where $y_{t}=(1+\theta) w_{t}+\theta r_{t}$ is aggregate factor income. Given the measure of each group in the

population, $\int \phi_{t}^{j} d j=\theta \phi_{t}^{\varepsilon}+\phi_{t}^{\rho}=1$. All members of each group are identical to one another. Each group differs from the other only by its factor endowment.

\subsection{Production}

The economy is competitive, both in production and factor markets. Production of each good requires both labor and land. Technology exhibits constant returns to scale and decreasing returns to each factor. As standard in the $\mathrm{H}-\mathrm{O}$ model, each good uses one of the factors relatively intensively. There are two sectors, each producing a different homogenous commodity. The goods are referred to as goods $\varepsilon$ and $\rho$ respectively, reflecting the fact that good $\varepsilon$ uses land intensively which is owned by the elite, while good $\rho$ uses labor intensively. There is free mobility of (the fixed aggregate supply of) each factor between sectors. This assumption underpins the fact that there is a single factor price equated to the value of that factor's marginal product. Denote the price of good $\varepsilon$ relative to good $\rho$ in period $t$ by $p_{t}$. Since the country is small, the world price of good $\varepsilon$ relative to good $\rho, p^{w}$, is taken as given. It will also be helpful later to have notation for the autarky price of $\operatorname{good} \varepsilon$ relative to good $\rho: p^{a}$. This approach implies that good $\rho$ is the numeraire in the model. If the economy is open then goods may be traded internationally but factors are not internationally mobile.

Output of good $i \in\{\varepsilon, \rho\}$ in period $t$ is denoted by $x_{i t}$. There is free entry into both sectors so that profits are driven to zero. Under these assumptions, given initial endowments, population shares and production technology, outputs and factor prices are determined by $p_{t}$, so we may write $w_{t}=w\left(p_{t}\right), r_{t}=r\left(p_{t}\right)$, and $x_{i t}=x_{i}\left(p_{t}\right)$ in period $t .^{11}$

\footnotetext{
${ }^{11}$ For compactness, where not relevant we will suppress the dependence of $x_{i t}$ on factor endowments. This dependency will become relevant when we discuss the cost of revolution.
} 
Since the structure of the economy is that of a standard $2 \times 2 \mathrm{H}-\mathrm{O}$ model, the standard results hold. We are particularly interested in the Stolper-Samuelson theorem, which demonstrates that if, in a given period, $p_{t}$ is increased then the real rental rate unambiguously increases while the real wage unambiguously decreases. Following Jones (1965), we can express the main implication of the Stolper-Samuelson theorem as follows: ${ }^{12}$

$$
r_{t}^{*}>p_{t}^{*}>0>w_{t}^{*}
$$

where a superscript- $*$ on a variable denotes proportional change, e.g. $r_{t}^{*}=d r_{t} / r_{t}$. Given our assumptions about endowments, we can translate this result into the effects of price changes on the incomes of the respective groups. But first we must specify the redistributive implications of trade policy, and to do that we must specify preferences.

\subsection{Preferences}

Agents $j \in\{\varepsilon, \rho\}$ have identical preferences and the same discount factor, $\beta<1$. The expected utility of agent $j$ at time 0 is given by:

$$
U_{0}^{j}=\mathbb{E}_{0} \sum_{t=0}^{\infty} \beta^{t} u\left(c_{\varepsilon t}^{j}, c_{\rho t}^{j}\right)
$$

where $\mathbb{E}_{t}$ is the expectations operator conditional on information available at time $t$. Utility in each period is given by the function $u\left(c_{\varepsilon t}^{j}, c_{\rho t}^{j}\right)$, which is strictly quasi-concave in goods $\varepsilon$ and $\rho$ respectively. Tastes are identical and homothetic, giving rise to well-behaved demand functions for agent $j, c_{i t}^{j}=c_{i}^{j}\left(p_{t}, Y_{t}^{j}\right)$, where $Y_{t}^{j}$ is total income of agent $j$. Furthermore, by homotheticity we may write $c_{i}^{j}\left(p_{t}, Y_{t}^{j}\right)=c_{i}\left(p_{t}\right) Y_{t}^{j} \cdot{ }^{13}$ We will denote aggregate demand for good $i$ by $c_{i t}$, where aggregate demand for good $i$ is given by the function $c_{i t}=c_{i}\left(p_{t}, Y_{t}\right)$ and $Y_{t}$ is aggregate income. Since all individuals have identical homothetic preferences, we may write $c_{i}\left(p_{t}, Y_{t}\right)=c_{i}\left(p_{t}\right) Y_{t}=\theta c_{i}\left(p_{t}\right) Y_{t}^{\varepsilon}+c_{i}\left(p_{t}\right) Y_{t}^{\rho}$. These assumptions on consumer behavior will help to establish the existence of well behaved optimal policies for each group.

\footnotetext{
${ }^{12}$ The conditions required for this relationship to hold globally are established by Chipman (1969) and the literature to which he refers. These conditions are assumed to hold throughout our analysis.

${ }^{13} \mathrm{~A}$ formal definition of $Y_{t}^{j}$ is provided below. For now note that it comprises factor income, $y_{t}^{j}$, and income from trade policy which will be defined below. Also note that $c_{i t}^{j}$ depends on the parameter $p^{w}$ via the effect of the world price on income. However, throughout the paper we will adopt the convention that parameters such as $p^{w}$ are suppressed from general functional notation.
} 


\subsection{Policy Instruments, Trade, and Income}

We will restrict the set of policy instruments to trade taxes. In principle, our model allows for a consideration of trade subsidies as well. But we will assume that there is no domestic fiscal capacity and so trade subsidies are not feasible. ${ }^{14}$ Trade taxes drive a wedge between the domestic price and the world price, both for consumers and for producers. For convenience, and without loss of generality, we will assume that trade policy is applied to good $\varepsilon$. Note that we have not specified the country's comparative advantage so good $\varepsilon$ could be either the country's exportable or its import-competing good. A domestic price in excess of the world price implies an import tariff for a good that is imported (and an export subsidy for one that is exported). A domestic price that is below the world price corresponds to an export tax for a good that is exported (and an import subsidy for one that is imported).

Concerning the redistribution of trade policy revenue, we will follow Mayer (1984) in assuming that this is neutral with respect to the overall distribution of income. Neutrality implies that agent $j$ 's share of total policy revenue in period $t$ is identical to agent $j$ 's factor income share in that period, as given by (1). ${ }^{15}$ So net trade policy revenue for an individual $j$ in period $t, t r_{t}^{j}$, is given by

$$
t r_{t}^{j}=\phi_{t}^{j} \cdot t r_{t}
$$

where $t r_{t}$ is aggregate trade policy revenue. Let $m_{t}=m\left(p_{t}, Y_{t}\right)=c_{\varepsilon}\left(p_{t}\right) Y_{t}-x_{\varepsilon}\left(p_{t}\right)$, with $m_{t}$ the quantity imported of good $\varepsilon$ in period $t$ and $m\left(p_{t}, Y_{t}\right)$ the corresponding import demand function. Then $\operatorname{tr}_{t}=\operatorname{tr}\left(p_{t}\right)=\left(p_{t}-p^{w}\right) m_{t}$. Note that, in the absence of revenue for trade subsidies, if the country has a comparative advantage in good $\rho$ then $m\left(p_{t}, Y_{t}\right) \geq 0$ and $p_{t} \geq p^{w}$ while if it has a comparative advantage in good $\varepsilon$ then $m\left(p_{t}, Y_{t}\right) \leq 0$ and $p_{t} \leq p^{w}{ }^{16}$ It follows that $t r_{t} \geq 0$.

\footnotetext{
${ }^{14}$ The assumption that domestic fiscal capacity is not available is intended to focus attention on trade policy as the sole policy instrument for redistribution. The results do not depend on the fact that trade subsidies are unavailable.

${ }^{15}$ This assumption plays essentially the same role as the more familiar assumption that tariff revenue is redistributed in lump-sum. In both cases, the purpose is to neutralize the role of trade policy revenue redistribution in the determination of group $j$ 's optimal trade policy. However, Mayer's neutrality assumption makes it clearer ex ante how tariff revenue will be redistributed. A redistribution rule that deviates from neutrality tends to give the group that gets a higher share of the revenue an interest in increasing the policy at the margin. An extreme version of this rule would give all revenue to the elite. This would parallel AR in their closed-economy one-sector setting, where the elite keep all tax revenue for themselves. Varying the share of trade policy revenue to the respective groups would not change our results qualitatively, but would affect the range of values of $\beta$ for which a 'revolution constraint' binds. See the discussion of the revolution constraint (15) below for details.

${ }^{16}$ Exports are denoted by negative imports.
} 
Finally, $Y_{t}$, measured in terms of good $\rho$, takes the form

$$
Y_{t}=(1+\theta) w\left(p_{t}\right)+\theta r\left(p_{t}\right)+\operatorname{tr}\left(p_{t}\right)=p_{t} x_{\varepsilon}\left(p_{t}\right)+x_{\rho}\left(p_{t}\right)+\left(p_{t}-p^{w}\right) m_{t} .
$$

Under homothetic preferences, we can solve simultaneously for $m_{t}$ and $Y_{t}$ :

$$
\begin{aligned}
m_{t} & =m\left(p_{t}\right)=\frac{c_{\varepsilon}\left(p_{t}\right)\left(p_{t} x_{\varepsilon}\left(p_{t}\right)+x_{\rho}\left(p_{t}\right)\right)-x_{\varepsilon}\left(p_{t}\right)}{1-\left(p_{t}-p^{w}\right) c_{\varepsilon}\left(p_{t}\right)} \\
Y_{t} & =Y\left(p_{t}\right)=\frac{p^{w} x_{\varepsilon}\left(p_{t}\right)+x_{\rho}\left(p_{t}\right)}{1-\left(p_{t}-p^{w}\right) c_{\varepsilon}\left(p_{t}\right)}
\end{aligned}
$$

Of course, $0<c_{\varepsilon}\left(p_{t}\right)<1$. By assumption for now, if $p_{t}>p^{w}$ then $\left(p_{t}-p^{w}\right)$ is sufficiently small that $\left(p_{t}-p^{w}\right) c_{\varepsilon}\left(p_{t}\right)<1$. This will be true in equilibrium. These forms clarify that we can express imports and total income strictly in terms of prices. Finally, we can define the total income of a member of group $j, Y_{t}^{j}$, as the sum of factor income and their share of trade policy revenue. Use the definitions of $y_{t}^{\varepsilon}$ and $y_{t}^{\rho}$ together with (1), (2), $w_{t}=w\left(p_{t}\right)$ and $r_{t}=r\left(p_{t}\right)$, to write total income for a member of group $j$ as ${ }^{17}$

$$
Y_{t}^{j}=Y^{j}\left(p_{t}\right)=\phi^{j}\left(p_{t}\right) Y\left(p_{t}\right)
$$

Expression (6) shows that the total income for a member of each group can be written as a product of aggregate income and a member of that group's income share, each term expressed as a function of $p_{t}$. This way of writing a member of each group's income will facilitate a clear characterization of that group's preferred trade policy in terms of $p_{t}$.

\subsection{Welfare of Each Group and its Preferred Price Level}

Using (6), the welfare of a member of group $j \in\{\varepsilon, \rho\}$ in period $t$ can be measured using the indirect utility function:

$$
W_{t}^{j}=W^{j}\left(p_{t}, Y^{j}\left(p_{t}\right)\right), j \in\{\varepsilon, \rho\}
$$

Adapting the approach developed by Mayer (1984) to the present context, each group's preferred trade policy can be determined from (7) and expressed in terms of $p_{t}$. Following this approach, we will say that group $j$ 's preferred price level, $\hat{p}^{j}$, is the value of $p_{t}$ that maximizes $W_{t}^{j}$. The

\footnotetext{
${ }^{17}$ In the following expressions we are defining the functions $\phi^{\varepsilon}\left(p_{t}\right)$ and $\phi^{\rho}\left(p_{t}\right)$ by substituting the functions $w_{t}=w\left(p_{t}\right)$ and $r_{t}=r\left(p_{t}\right)$ into the definitions of $\phi_{t}^{\varepsilon}$ and $\phi_{t}^{\rho}$ implied by (1).
} 
first order condition from which $\hat{p}^{j}$ is obtained can be expressed as: ${ }^{18}$

$$
f o c^{j}\left(p_{t}\right)=\frac{d W_{t}^{j}}{d p_{t}}=\frac{\partial W_{t}^{j}}{\partial Y_{t}^{j}}\left(\phi^{j}\left(p_{t}\right)\left(p_{t}-p^{w}\right) \frac{\partial m_{t}}{\partial p_{t}}+Y\left(p_{t}\right) \frac{\partial \phi_{t}^{j}}{\partial p_{t}}\right)=0 .
$$

The first term in the brackets represents the share borne by individual $j$ of the aggregate distortion resulting from protection: ' $j$ 's distortion share' for short. The second term in brackets captures the redistributive 'Stolper-Samuelson effect' of trade policy on individual $j$ 's factor income: the 'Stolper-Samuelson effect on $j$ ' for short. Assume that $\partial^{2} W_{t}^{j} / \partial p_{t}^{2}<0$, so that there is a unique value, $p_{t}=\hat{p}^{j}$, that sets $f o c^{j}\left(\hat{p}^{j}\right)=0$. Solving (8) for $\hat{p}^{j}$ :

$$
\hat{p}^{j}=p^{w}-\frac{Y\left(p_{t}\right)}{\partial m_{t} / \partial p_{t}} \frac{\partial \phi_{t}^{j} / \partial p_{t}}{\phi^{j}\left(p_{t}\right)}, j \in\{\varepsilon, \rho\}
$$

The solution to $\hat{p}^{j}$ may imply a trade tax or trade subsidy. To fully understand this solution, we will first assume that the fiscal capacity exists to implement $\hat{p}^{j}$ as an interior solution. We will then move on to consider the implementation of $\hat{p}^{j}$ in the absence of fiscal capacity, in which case it may have to be implemented as a corner solution. Since $Y\left(p_{t}\right),-\partial m_{t} / \partial p_{t}$, and $\phi^{j}\left(p_{t}\right)$ are positive, the question of whether $\hat{p}^{j}$ lies above or below $p^{w}$ is determined solely by the sign of $\partial \phi_{t}^{j} / \partial p_{t}$ for $\varepsilon$ and $\rho$ respectively. Differentiating $\phi^{\varepsilon}\left(p_{t}\right)$ and $\phi^{\rho}\left(p_{t}\right)$ in turn with respect to $p_{t}$, we obtain:

$$
\begin{aligned}
\frac{\partial \phi_{t}^{\varepsilon}}{\partial p_{t}} & =\frac{w\left(p_{t}\right) \cdot r\left(p_{t}\right)}{\left((1+\theta) w\left(p_{t}\right)+\theta r\left(p_{t}\right)\right)^{2} p_{t}}\left(\frac{r_{t}^{*}-w_{t}^{*}}{p_{t}^{*}}\right)>0 ; \\
\frac{\partial \phi_{t}^{\rho}}{\partial p_{t}} & =-\frac{\theta \cdot w\left(p_{t}\right) \cdot r\left(p_{t}\right)}{\left((1+\theta) w\left(p_{t}\right)+\theta r\left(p_{t}\right)\right)^{2} p_{t}}\left(\frac{r_{t}^{*}-w_{t}^{*}}{p_{t}^{*}}\right)<0 .
\end{aligned}
$$

Using these results with (9), we can conclude that $\hat{p}^{\varepsilon}>p^{w}>\hat{p}^{\rho}$. For this solution to make sense, we can always fix $p^{w}$ sufficiently large that $\hat{p}^{\rho}>0$. Further discussion of how $\hat{p}^{\varepsilon}$ and $\hat{p}^{\rho}$ are determined is provided in Appendix A.2. ${ }^{19}$

The relationship between the determination of $\hat{p}^{\varepsilon}$ and $\hat{p}^{\rho}$ is illustrated in Figures 1 and 2. With a comparative advantage in good $\varepsilon, p^{w}>p^{a}$, as illustrated in Figure 1. The downward

\footnotetext{
${ }^{18}$ See Appendix A.1 for further details on how this first order condition is derived. Since the solution for $\hat{p}^{j}$ is obtained by finding the value of $p_{t}$ at which the expression inside the brackets is equal to zero, we do not strictly need the term $\partial W_{t}^{j} / \partial Y_{t}^{j}$ in $f o c^{j}\left(p_{t}\right)$. However, later we will evaluate the effect of a world price shock on $\hat{p}^{j}$ and, in differentiating $f o c^{j}\left(p_{t}\right)$ with respect to $p^{w}$, it will be necessary to incorporate the term $\partial W_{t}^{j} / \partial Y_{t}^{j}$.

${ }^{19}$ The driving force behind the results that $\partial \phi_{t}^{\varepsilon} / \partial p_{t}>0$ and $\partial \phi_{t}^{\rho} / \partial p_{t}<0$ is the familiar Stolper-Samuelson effect. That is, the elite are relatively well endowed with land while the rest of society are relatively well endowed with labor, so an increase in the relative price of the land-intensive good, $p_{t}$, increases the income share of the elite and reduces that of the rest of society. Thus agents in our model lie either side of the benchmark agent introduced in Mayer (1984) whose factor endowments were equal to the average for the nation as a whole and therefore whose factor income share would not change as a result of a change in $p_{t}$.
} 
sloping lines show $d W_{t}^{\varepsilon} / d p_{t}$ and $d W_{t}^{\rho} / d p_{t}$, as given by (8). The point where each crosses the horizontal axis determines $\hat{p}^{\varepsilon}$ and $\hat{p}^{\rho}$ respectively, as given by (9). In this situation, the elite's welfare is maximized at a higher level of openness than is the rest of society's. This stands to reason since, when the country has a comparative advantage in good $\varepsilon$, the elite own the factor used intensively in the production of the good for which the country has a comparative advantage. Therefore, the elite's factor income is increasing in the level of openness whereas the rest of society's is decreasing. Indeed, since $\hat{p}^{\varepsilon}>p^{w}$, the elite would ideally like an export subsidy that increases the price received for each unit of good $\varepsilon$ above the world price. Under our assumption that trade subsidies are not possible, the elite could do no better than to settle for a corner solution at free trade, $p^{w}$. Turning to $\hat{p}^{\rho}$, with Figure 1 being drawn in such a way that $\hat{p}^{\rho}>p^{a}$, the interior solution implies that the rest of society would ideally like an export tax on good $\varepsilon$ that allows some openness. But, depending on their relative preferences for goods $\varepsilon$ and $\rho$, it could equally be the case that $\hat{p}^{\rho}<p^{a}$. In that case, the rest of society would ideally like an import subsidy on good $\varepsilon$ so large that it overturned the country's natural comparative advantage. But without the domestic fiscal capacity to raise the revenue required, in this situation they could do no better than autarky.

With a comparative advantage in $\operatorname{good} \rho, p^{a}>p^{w}$, as illustrated in Figure 2. In that case the rest of society's welfare is maximized at a higher level of openness than is the elite's. With a comparative advantage in good $\rho$, it is the factor income of the rest of society that is increasing in the level of openness, and so the rest of society prefers a higher level of openness in general. And it is the preferred price level of the rest of society, $\hat{p}^{\rho}<p^{w}$, that would necessarily imply an import subsidy if the domestic fiscal capacity were available to raise the revenue. In its absence, the rest of society could do no better than to settle for free trade. As drawn in Figure $2, \hat{p}^{\varepsilon}<p^{a}$ is at an interior solution implying an import tariff, but $\hat{p}^{\varepsilon}>p^{a}$ is equally feasible and would imply an export subsidy on good $\varepsilon$ large enough to overturn the country's natural comparative advantage in good $\rho$. But in the absence of domestic fiscal capacity, the elite could do no better than to settle for autarky. This analysis is summarized as follows.

Proposition 1. With domestic fiscal capacity available, $\hat{p}^{\rho}<p^{w}<\hat{p}^{\varepsilon}$ regardless of comparative advantage. If domestic fiscal capacity is absent then:

(i) with a comparative advantage in good $\varepsilon, \hat{p}^{\varepsilon}=p^{w}$ while $p^{a} \leq \hat{p}^{\rho}<p^{w}$;

(ii) with a comparative advantage in $\operatorname{good} \rho, \hat{p}^{\rho}=p^{w}$ while $p^{w}<\hat{p}^{\varepsilon} \leq p^{a}$. 
From this result we can see that the level of openness preferred by the respective groups is determined by which group owns the factor used intensively in the good for which the country has a comparative advantage. ${ }^{20}$ Proposition 1 also reveals that the availability or otherwise of domestic fiscal capacity for trade subsidies plays a role in the characterization of $\hat{p}^{\varepsilon}$ and $\hat{p}^{\rho}$. We will explain where relevant how equilibrium outcomes are affected by an absence of domestic fiscal capacity.

\subsection{Efficiency}

Following the utilitarian notion of efficiency, we will use the total surplus available for distribution to citizens in any given period, $\Omega_{t}$ :

$$
\Omega_{t}=\theta u\left(c_{\varepsilon t}^{\varepsilon}, c_{\rho t}^{\varepsilon}\right)+u\left(c_{\varepsilon t}^{\rho}, c_{\rho t}^{\rho}\right)
$$

Appendix A.3 establishes that incremental trade liberalization is associated with an increase in economic efficiency. It is of course well known that, in a standard competitive trade model, free trade maximizes efficiency. In our model, differently from the standard set-up, we rule out all redistributive policy except for trade policy itself. We are also considering incremental changes in trade policy rather than a move between autarky and free trade. So it may be helpful to know that trade liberalization does imply an increase in efficiency under these restrictions as well.

\section{Trade Policy and the Form of Government}

We will now endogenize $p_{t}$ by combining the H-O model set out above with the model of the form of government developed by AR. Recall that our aim is to explore the role that trade policy could play to defuse a revolution, both in terms of franchise extension and in terms of forestalling democratization. To preview the framework that we will develop in terms of the analysis so far, first note that, with no threat of revolution, the elite will set their preferred trade policy, $\hat{p}^{\varepsilon}$. If the rest of society attain democracy, either through extension of the franchise or through revolution, they are able to set the trade policy they would prefer in all periods, $\hat{p}^{\rho}$. The elite would like to forestall democratization in order to avoid $\hat{p}^{\rho}$. To forestall democratization,

\footnotetext{
${ }^{20}$ The conflict of interest between groups over trade policy is of course more general than the framework we are using here. Our framework could be extended to consider any number of goods and factors. However, this would obscure the simple logic of the revenue considerations of trade policy that we will be able to bring out in the $2 \times 2$ case.
} 
the elite must use trade policy to make concessions to the rest of society so that their payoff from maintaining the status quo is at least as high as from revolution. But at the time they face the threat of revolution, the elite may not be able to credibly commit to trade policy that makes the rest of society at least as well off as under revolution: the commitment problem. If they cannot, it is better for the elite to concede democratization through extension of the franchise than face revolution, because extension of the franchise avoids the cost of revolution.

What determines whether the elite face a commitment problem and hence must extend the franchise? The elite will not face a commitment problem if they can use trade policy to set a status quo price, $p^{s}$, that equates the rest of society's payoff under the status quo with what they would obtain from mounting a revolution. Because revolution is costly, $p^{s}$ does not have to equal $\hat{p}^{\rho}$. It will lie somewhere between $\hat{p}^{\varepsilon}$ and $\hat{p}^{\rho}$. The commitment problem may arise because, at the time the threat of revolution occurs, the elite can only credibly commit to set $p^{s}$ in any future period where the threat of revolution reoccurs. With no threat of revolution, the elite cannot credibly commit to set anything other than $\hat{p}^{\varepsilon}$. If the threat of revolution is expected to arise sufficiently frequently in the future, then the elite will be able to set $p^{s}$ with sufficient frequency in the future to give the rest of society at least as high a payoff as from revolution. Then the elite will be able to use trade policy to forestall democratization. It is when the threat of revolution is expected to arise only rarely in future that the elite will not be able to commit to set $p^{s}$ with sufficient frequency to provide a payoff as high as revolution. Then the elite do face a commitment problem, and extension of the franchise represents the only way for the elite to commit to policy that gives the rest of society at least as high a payoff as they would obtain from revolution.

Let us now develop a formal framework to discuss these ideas. Initially, (de jure) political power is held by the elite. The elite can exercise this power in the model through their control of trade policy. Under this specification, and for parsimony of notation, we will say that while the elite hold power they set $p_{t}$ directly. Denote the value of $p_{t}$ chosen by the elite as $p_{t}^{\varepsilon}$. Assume that, in any given period $t$, with probability $\kappa$ the rest of society are able to resolve the coordination problem involved in mounting a revolution and hence are in a position to mount a revolution. We will refer to this as the 'high threat state' or $H$. On the other hand, with probability $1-\kappa$ the rest of society are unable to resolve their coordination problem and hence pose no threat to the elite; the 'low threat state' or $L$. If in period $t$ the threat level is $L$, then 
since there is no threat of revolution the elite can set $p_{t}^{\varepsilon}$ at $\hat{p}^{\varepsilon}$ with impunity. If the threat level is $H$ then the elite can respond in one of two ways. They can voluntarily extend the franchise which ushers in democracy, or they can use trade policy to set the status quo price, $p^{s}$, that is favorable to the rest of society to try to maintain the status quo. ${ }^{21}$

If the threat level is $H$ and the rest of society mount a revolution then it is successful for sure. Revolution allows the rest of society to install democracy through which the median voter determines trade policy, $p_{t}$. Given $\theta<1$, under democracy the median voter is a member of the rest of society, whose preferred price level is $\hat{p}^{\rho}$. So democratization implies a transfer of power to set trade policy between the groups. ${ }^{22}$ The same outcome of democracy can arise if the elite decide voluntarily to extend the franchise. Since revolution and franchise extension both lead to democracy, the form of government, $F$, is either democracy, $D$, or elite rule, $E$. Denote the state in a given period by the tuple $(F ; s)$, where $F \in\{E, D\}$ and $s \in\{H, L\}$.

Both groups would prefer to avoid revolution because it is costly. Collier (1999) characterizes three types of economic cost that arise from such conflicts: diversion, destruction, and disruption. Diversion refers to the use of resources for armament instead of other things; destruction is perhaps the most obvious cost of conflict; disruption refers to difficulties with allocating resources effectively that arise as a result of conflict. In our formalization we will focus on the 'disruption cost' arising from revolution. Assume that if revolution takes place then, in that period, only a share $\psi l=\psi(1+\theta)$ of labor and $\psi \lambda=\psi \theta$ of land can be allocated to production, where $\psi<1$. This effectively implies a radial contraction of the production possibility frontier in the period of revolution. Therefore, revolution results in the same proportional loss of income to both groups. In the period after revolution and thereafter, full allocation of labour and land to production, $l=1+\theta$ and $\lambda=\theta$, is restored. ${ }^{23}$

\footnotetext{
${ }^{21}$ It is straight forward to extend this framework to allow the elite a third option of using repression. The simple basic insight one obtains from doing so is that the elite will repress when it is the cheapest option.

${ }^{22}$ Thus, in the present model, revolution would result only in a transfer of (de jure) political power from the elite to the rest of society. In AR, revolution would also result in a transfer of elite endowments to the rest of society as well. Adopting this assumption would not change the qualitative results of the present model. It is similar to the case discussed in footnote 15 where the elite retain all trade policy revenue and spend it as they see fit. Transferring all elite endowments to the rest of society in a revolution would only affect the range of values of $\beta$ for which a 'revolution constraint' binds; see the discussion following (15).

${ }^{23}$ In an earlier version of the paper, I modelled the cost of revolution as being directly proportional to income itself rather than factor endowments. That approach reflected more closely the first and second costs of revolution: diversion and destruction. While the results were isomorphic to those of the present paper, they required further restrictions on the production technology and so held under less general conditions.
} 
The game is initialized with the assumption that in period 0 there is rule by the elite. Within a period, $t$, the sequence of events is as follows.

1. The world price, $p^{w}$, and the threat level to the elite regime $s \in\{H, L\}$ are revealed.

2. The elite decide whether or not to extend the franchise. If they do then there is democracy. If they do not, they set trade policy, $p_{t}=p_{t}^{\varepsilon}$.

3. If $s=H$ and the elite have not extended the franchise then the rest of society decide whether or not to mount a revolution. If they do so it is successful for sure, leading to democracy.

4. If there is democracy then trade policy $p_{t}=\hat{p}^{\rho}$ is set by the median voter (a member of the rest of society).

5. Production takes place, demands are realized, markets clear and consumption takes place.

Some additional assumptions are needed to complete the specification of the model. Once a shock to $p^{w}$ has been realized then it is expected to remain at its new level indefinitely. If democracy arises in period $t$ then, since it is an absorbing state (i.e. it cannot be rescinded), from $t+1$ onwards the sequence of events starts from stage 4 . In that case the state $s$ is no longer relevant. Otherwise the game starts again from stage $1 .^{24}$ The fact that all members of each of the two respective groups, the elite and the rest of society, are identical to one another (but obviously differ across groups by their endowments) makes the analysis of the game simpler because we can model the members of each group as a single player. So we can model the situation set out above as a two-player game between the elite and the rest of society.

From the sequence of events above, we can see that the characterization of equilibrium involves comparing the payoffs of the elite and the rest of society under the status quo, extension of the franchise, and revolution. A challenge arises with making these comparisons from the fact that $\hat{p}^{j}$ may be different under revolution than under the status quo and extension of the franchise. Observe from (9) that $\hat{p}^{j}$ depends on $Y\left(p_{t}\right), \partial m_{t} / \partial p_{t}, \phi^{j}\left(p_{t}\right)$ and $\partial \phi_{t}^{j} / \partial p_{t}$, all of which could in principle be affected by the costs of revolution. But our characterization of the

\footnotetext{
${ }^{24}$ The assumption that democracy is an absorbing state enables us to focus the analysis on whether or not it is possible to set trade policy to forestall democratization. Acemoglu and Robinson (2001) present a model where democracy may fail to consolidate, and the present model could straight-forwardly be extended in that direction. Galiani and Torrens (2014) allow for this possibility, with interesting policy implications.
} 
cost of revolution as a radial contraction of the production possibility frontier ensures that $\hat{p}^{j}$ is unaffected by revolution. Firstly, the fact that in the period of revolution both factors are reduced in the same proportion, $\psi$, implies that agent $j$ 's overall income share does not change. Consequently, both $\phi^{j}\left(p_{t}\right)$ and $\partial \phi_{t}^{j} / \partial p_{t}$ are the same in (9) under revolution as they are in the absence of revolution. Secondly, $Y\left(p_{t}\right)$ and $\partial m_{t} / \partial p_{t}$ are reduced in the same proportion, as a result of which $Y\left(p_{t}\right) /\left(\partial m_{t} / \partial p_{t}\right)$ is unaffected by revolution as well. The result follows.

Proposition 2. Assume that revolution imposes a disruption cost in the period when revolution occurs, that reduces the labor and land that can be allocated to production by the same proportion, $\psi<1$. $Y\left(p_{t}\right)$ and $\partial m_{t} / \partial p_{t}$ are each homogeneous of degree one in labor and land, and so $Y\left(p_{t}\right) /\left(\partial m_{t} / \partial p_{t}\right)$ is homogeneous of degree zero in labor and land. Consequently, the solution for $\hat{p}^{j}$ given by (9) is invariant to the occurrence of revolution.

See Appendix A.4 for a formal proof. Adapting an approach developed by Syropoulos (2002), the proof uses the fact that, in the $\mathrm{H}-\mathrm{O}$ model, the underlying revenue function for a country is linearly homogeneous in factors. This implies that the output of each good, $x_{i t}$, and its supply response to a price change, are linearly homogeneous in factors as well. In the present setting, this implies that both $Y\left(p_{t}\right)$ and $\partial m_{t} / \partial p_{t}$ are linearly homogeneous in labor and land. So their ratio must be homogeneous of degree zero. This is the basis on which we can say that the solution to $\hat{p}^{j}$ given by (9) is invariant to the occurrence of revolution. ${ }^{25}$

A useful implication of Proposition 2 is that, by their linear homogeneity in factors, $x_{\varepsilon t}$ and $x_{\rho t}$ are both unambiguously lower in the event of a revolution than otherwise. Using (5) and (6), and denoting a member of group $j$ 's income under revolution by $Y_{R}^{j}\left(p_{t}\right)$, we can see straight away that for given $p^{w}, Y_{R}^{j}\left(\hat{p}^{\rho}\right)=\psi Y^{j}\left(\hat{p}^{\rho}\right) .{ }^{26}$ So the disruption cost to agent $j$ can be written in terms of income as $Y^{j}\left(\hat{p}^{\rho}\right)-Y_{R}^{j}\left(\hat{p}^{\rho}\right)=(1-\psi) Y^{j}\left(\hat{p}^{\rho}\right)$. This feature will be useful in the characterization of equilibrium.

\footnotetext{
${ }^{25}$ Note that in Section 4 we will analyze comprehensively the effects of a shock to $p^{w}$ on $\hat{p}^{j}$. This analysis will give us a clear sense of how $\hat{p}^{j}$ can change endogenously and how such a change affects the wider economy.

${ }^{26}$ As before, when $p_{t}=\hat{p}^{\rho}, Y^{j}\left(\hat{p}^{\rho}\right)$ denotes agent $j$ 's income under full factor supplies.
} 


\subsection{Definition of Equilibrium, Payoffs, and the Commitment Problem}

The concept of equilibrium we will use is that of Markov Perfection, wherein each player's strategy depends only on the state $(F ; s)$ in a given period. ${ }^{27}$ The strategies played by the respective groups are as follows. The strategy $\sigma^{\varepsilon}(F ; s)$ played by the elite consists of the choice over whether or not to extend the franchise, and how to set trade policy. Let $f=0$ if the elite do not extend the franchise (in which case $p_{t}^{\varepsilon}$ is their choice of trade policy) and $f=1$ if they do. Let $\sigma^{\rho}\left(F \mid\left(f, p_{t}^{\varepsilon}\right) ; s\right)$ be the strategy played by the rest of society in response to the choices $f$ and $p_{t}^{\varepsilon}$ by the elite. This consists of the rest of society's decision as to whether or not to mount a revolution: $a=1$ if they do (where $a$ is a mnemonic for 'agitate') and 0 otherwise. Since, by the timing of events determined above, the elite move before the rest of society, the strategy of the rest of society in a given period is conditioned on that of the elite. Let $\widetilde{\sigma}^{\varepsilon}(F ; s)$ be a best response to $\sigma^{\rho}\left(F \mid\left(f, p_{t}^{\varepsilon}\right) ; s\right)$ for all $F, s$, and let $\widetilde{\sigma}^{\rho}\left(F \mid\left(f, p_{t}^{\varepsilon}\right) ; s\right)$ be a best response to $\sigma^{\varepsilon}(F ; s)$ for all $F, s$. Then a pure strategy Markov Perfect equilibrium is a set of mutual best responses $\left\{\widetilde{\sigma}^{\varepsilon}(F ; s), \widetilde{\sigma}^{\rho}\left(F \mid\left(f, p_{t}^{\varepsilon}\right) ; s\right)\right\}$.

To examine which outcome will arise in equilibrium, we will now formalize the payoffs to the respective groups under the various possible outcomes. Let $V^{j}\left(D, \hat{p}^{\rho}\right)$ represent the present discounted value under democracy for $j \in\{\varepsilon, \rho\}$. For a member of group $j$, the payoff to democracy via an extension of the franchise takes the form:

$$
V^{j}\left(D, \hat{p}^{\rho}\right) \equiv \frac{W^{j}\left(\hat{p}^{\rho}, Y^{j}\left(\hat{p}^{\rho}\right)\right)}{1-\beta} .
$$

where the term $1-\beta$ provides the net present value when, under democracy, trade policy is chosen by the median voter as $p_{t}=\hat{p}^{\rho}$. Extending the franchise carries no cost and makes an appealing offer to the rest of society in that it represents a way for the elite to make a credible commitment to $\hat{p}^{\rho}$ in the current and all future periods.

Denoting the occurrence of revolution by $R$, the payoff to revolution is given by

$$
V^{j}\left(R, \hat{p}^{\rho}\right) \equiv W^{j}\left(\hat{p}^{\rho}, Y_{R}^{j}\left(\hat{p}^{\rho}\right)\right)+\beta \frac{W^{j}\left(\hat{p}^{\rho}, Y^{j}\left(\hat{p}^{\rho}\right)\right)}{1-\beta} .
$$

where the first term captures agent $j$ 's payoff in the period of revolution and the second term captures the discounted payoff in subsequent periods. Clearly, given $p_{t}=\hat{p}^{\rho}$ for all $t$, both groups

\footnotetext{
${ }^{27}$ In our set-up, any Markov Perfect Equilibrium (MPE) coincides with Subgame Perfect Equilibrium (SPE). The reason is that the returns to the various strategies open to the elite are independent of history. Since MPE conditions only on current states, a different outcome could be obtained under SPE if the elite were able to choose different strategies contingent on past outcomes.
} 
would prefer an extension of the franchise to revolution because this avoids the disruption cost of revolution $(1-\psi) Y^{j}\left(\hat{p}^{\rho}\right)$. Therefore, extension of the franchise always has the potential to defuse revolution. But the elite can use trade policy to defuse the threat of revolution if the rest of society's payoff under trade policy set by the elite is at least as high as under revolution.

We are now ready to formalize the commitment problem. The following 'revolution constraint' provides a necessary (but not sufficient) condition for the elite to face a commitment problem. Assuming that in period $t$ the state is $H$, the revolution constraint is binding if:

$$
\begin{aligned}
& W^{\rho}\left(\hat{p}^{\rho}, Y_{R}^{\rho}\left(\hat{p}^{\rho}\right)\right)+\beta \frac{W^{\rho}\left(\hat{p}^{\rho}, Y^{\rho}\left(\hat{p}^{\rho}\right)\right)}{1-\beta} \\
> & W^{\rho}\left(\hat{p}^{\rho}, Y^{\rho}\left(\hat{p}^{\rho}\right)\right)+\beta \frac{W^{\rho}\left(\hat{p}^{\varepsilon}, Y^{\rho}\left(\hat{p}^{\varepsilon}\right)\right)}{1-\beta} .
\end{aligned}
$$

Notice that the first line is equal to the payoff to revolution for the rest of society given by (14), while the second line gives their payoff from a single period of $\hat{p}^{\rho}$ followed by an indefinite return to $\hat{p}^{\varepsilon}$. By construction, $W^{\rho}\left(\hat{p}^{\rho}, Y_{R}^{\rho}\left(\hat{p}^{\rho}\right)\right)<W^{\rho}\left(\hat{p}^{\rho}, Y^{\rho}\left(\hat{p}^{\rho}\right)\right)$ while $W^{\rho}\left(\hat{p}^{\rho}, Y^{\rho}\left(\hat{p}^{\rho}\right)\right)>$ $W^{\rho}\left(\hat{p}^{\varepsilon}, Y^{\rho}\left(\hat{p}^{\varepsilon}\right)\right)$. Therefore, for given disruption cost $(1-\psi) Y^{j}\left(\hat{p}^{\rho}\right)$, the revolution constraint fails for $\beta$ sufficiently small and binds for $\beta$ sufficiently large. That is, the rest of society must care enough about the future that they obtain a higher payoff from revolution despite the cost, because they are able to set more favorable trade policy $\hat{p}^{\rho}$ over time, than they would from a single period of favorable trade policy today, $\hat{p}^{\rho}$, followed by unfavorable trade policy in the future, $\hat{p}^{\varepsilon}$. If the revolution constraint fails, then the elite can induce a higher level of welfare for the rest of society by setting $\hat{p}^{\rho}$ for a single period than they could obtain through revolution. Therefore, the elite could in fact use trade policy to set a price $p_{t}^{\varepsilon}>\hat{p}^{\rho}$ that equates the two sides of (15) for a single period to completely defuse the threat of revolution. Then the commitment problem does not arise because the elite can completely defuse the threat of revolution within a single period.

If $\beta$ is sufficiently large that the revolution constraint binds, then the elite cannot simply defuse the threat of revolution with a single period's trade policy that is favorable to the rest of society. When the revolution constraint binds, the elite must set $\hat{p}^{\rho}$ for multiple periods to raise the rest of society's payoff above the level they would obtain through a revolution. But during some of these periods the state may switch to $L$, during which the elite will only be able to credibly commit to set $\hat{p}^{\varepsilon}$. If $L$ is expected to occur with sufficient frequency, the elite will not be able to credibly commit to induce a level of welfare for the rest of society that is as high 
as they could obtain from revolution: the elite face a commitment problem. This is the sense in which the revolution constraint provides a necessary (but not sufficient) condition for the commitment problem to arise. ${ }^{28}$

Assume from now on that we choose a value of $\beta$ so that the revolution constraint binds. The question of whether or not the elite face a commitment problem comes down to whether the elite can set a status quo price $p^{s} \in\left[\hat{p}^{\rho}, \hat{p}^{\varepsilon}\right)$ in every occurrence of $H$ to yield exactly the same payoff for the rest of society as under revolution. If they cannot then they face a commitment problem. To evaluate this, we need to be able to calculate agent $j$ 's payoff under the status quo:

$$
V^{j}\left(E, p^{s} ; H\right) \equiv W^{j}\left(p^{s}, Y^{j}\left(p^{s}\right)\right)+\beta\left(\kappa V^{j}\left(E, p^{s} ; H\right)+(1-\kappa) V^{j}\left(E, \hat{p}^{\varepsilon} ; L\right)\right)
$$

The first term on the right hand side of (16) shows the payoff to agent $j$ in the current period, when the elite set $p^{s}$. The second term shows the expected payoff in the following period, which is discounted by $\beta$. If (with probability $\kappa$ ) in the following period the state of $H$ is maintained then the elite will continue to set $p^{s}$ and agent $j$ 's utility will be maintained at the same level. But if (with probability $1-\kappa$ ) the state switches to $L$ then the elite will (renege on any promise to maintain redistribution with $p^{s}$ and) restore their preferred price level $\hat{p}^{\varepsilon}$. Solving recursively, $V^{j}\left(E, p^{s} ; H\right)$ is then given by

$$
V^{j}\left(E, p^{s} ; H\right)=\frac{1-\beta(1-\kappa)}{1-\beta} W^{j}\left(p^{s}, Y^{j}\left(p^{s}\right)\right)+\frac{\beta(1-\kappa)}{1-\beta} W^{j}\left(\hat{p}^{\varepsilon}, Y^{j}\left(\hat{p}^{\varepsilon}\right)\right)
$$

The first term on the right hand side measures the payoff to agent $j$ from $p^{s}$ weighted by the expected frequency of state $H$, and the second term similarly for $\hat{p}^{\varepsilon}$ given the expected frequency of state $L$. So the sum of these terms gives the expected payoff to agent $j$ from maintaining the status quo.

To find $p^{s}$, first define the function

$$
G\left(p^{\varepsilon}\right) \equiv V^{\rho}\left(E, p^{\varepsilon} ; H\right)-V^{\rho}\left(R, \hat{p}^{\rho}\right)
$$

where $p^{\varepsilon}$ replaces $p^{s}$ in (17). Then by definition the status quo price, $p^{s}$, solves $G\left(p^{s}\right)=0$. This specification formalizes the idea that to maintain the status quo the elite set $p^{s}$ so that the rest of society are just indifferent between mounting a revolution and not doing so.

\footnotetext{
${ }^{28}$ If we allowed the elite to use some of their income, say from tariff revenue, to make direct transfers to the rest of society in the current period to defuse the threat of revolution, this would increase the value of $\beta$ necessary to get the revolution constraint to bind. Relatedly, allowing the rest of society to seize the elite's assets in a revolution would increase the size of the terms on the first line of the revolution constraint, thus reducing the necessary size of $\beta$. But again, the analysis would not be affected in a qualitative way.
} 
Now that we have specified the commitment problem and payoff functions, we can complete the formalization of the game. According to the above definition of equilibrium, given $H$, the elite first decide whether to extend the franchise, $f=1$, or whether to use trade policy to maintain the status quo, $f=0$ and $p_{t}^{\varepsilon}=p^{s}$. Given either of these two actions by the elite, a member of the rest of society's strategy, $a=0$ or $a=1$, solves the problem

$$
\max \left\{f V^{\rho}\left(D, \hat{p}^{\rho}\right)+(1-f) V^{\rho}\left(E, p^{s} ; H\right), V^{\rho}\left(R, \hat{p}^{\rho}\right)\right\}
$$

The rest of society obtain the first term in brackets if they choose $a=0$ and the second term if they choose $a=1$. With the game formalized in this way, the characterization of equilibrium is straightforward. This involves evaluating whether or not the elite face a commitment problem. If they do not, they can use trade policy to avoid a revolution (i.e. set $f=0$ ) and if they do then they must extend the franchise in order to do so (i.e. set $f=1$ ).

\subsection{Characterization of Equilibrium}

To characterize equilibrium, we will now take the first step of examining when the elite face a commitment problem and hence must extend the franchise. They face a commitment problem if, in state $H$, it is not feasible for them to use trade policy to maintain the status quo. To examine feasibility, let $\widetilde{V}^{\rho}(E \mid \kappa ; H)$ be the maximum utility that the elite can induce for the rest of society using trade policy (as an alternative to extending the franchise). This is induced by setting $\hat{p}^{\rho}$ in every period where $H$ arises, and setting $\hat{p}^{\varepsilon}$ in every period where $L$ arises: formally, by setting $p^{s}=\hat{p}^{\rho}$ in $(17), \widetilde{V}^{\rho}(E \mid \kappa ; H) \equiv V^{\rho}\left(E, \hat{p}^{\rho} ; H\right)$. Then the condition for the

elite to face a commitment problem is $\widetilde{V}^{\rho}(E \mid \kappa ; H)<V^{\rho}\left(R, \hat{p}^{\rho}\right)$. Building on the approach developed by AR, the next result establishes that there exists a critical level of $\kappa$, denoted $\bar{\kappa}$, at which the elite are just able to prevent a revolution using trade policy; for $\kappa<\bar{\kappa}$ the elite face a commitment problem and for $\kappa>\bar{\kappa}$ they do not.

Lemma 1. Assume a value of $\beta$ for which the revolution constraint binds. Then for $\psi<1$ there exists a (unique) $\bar{\kappa} \in(0,1)$ at which $\widetilde{V}^{\rho}(E \mid \kappa ; H)=V^{\rho}\left(R, \hat{p}^{\rho}\right)$.

1. For all $\kappa<\bar{\kappa}, \widetilde{V}^{\rho}(E \mid \kappa ; H)<V^{\rho}\left(R, \hat{p}^{\rho}\right)$ : over this range of $\kappa$ it is not feasible to use trade policy to prevent a revolution so the elite face a commitment problem.

2. For all $\kappa>\bar{\kappa}, \widetilde{V}^{\rho}(E \mid \kappa ; H)>V^{\rho}\left(R, \hat{p}^{\rho}\right)$ : over this range of $\kappa$ it is feasible to use trade policy to prevent a revolution so the elite do not face a commitment problem. 
See Appendix A.4 for a formal proof. The logic of Lemma 1 is illustrated in Figure 3, which shows the present discounted value of the rest of society's expected welfare when the state is $H$. For any value of $\kappa \in[0,1]$, the figure compares the maximum level of expected welfare that the elite can induce for the rest of society using trade policy with the payoff the rest of society can get from an extension of the franchise and from revolution.

The value of $\kappa$ is shown in Figure 3 on the horizontal axis while the present discounted value of the rest of society's expected welfare level is on the vertical axis. The horizontal dashed line shows the payoff to the rest of society from an extension of the franchise, as calculated by (13). The horizontal solid line shows the payoff to revolution, $V^{\rho}\left(R, \hat{p}^{\rho}\right)$, given by (14). The vertical difference between them is proportional to the cost of revolution, $(1-\psi) Y^{\rho}\left(\hat{p}^{\rho}\right)$. If we allowed $\psi=1$ then the two lines would coincide, while the smaller is $\psi<1$ the lower is the solid line relative to the dashed line. The upward sloping line shows $\widetilde{V}^{\rho}(E \mid \kappa ; H)$. The intercept of $\widetilde{V}^{\rho}(E \mid \kappa ; H)$ with the vertical axis, where $\kappa=0$, corresponds to the payoff that the rest of society receive from a policy of $\hat{p}^{\rho}$ in the current period followed by reversion to $\hat{p}^{\varepsilon}$ for all periods in the future. This is the payoff given by the second line of the revolution constraint, (15). Recall that we have chosen a value of $\beta$ such that the revolution constraint binds. This implies that the intercept of $\widetilde{V}^{\rho}(E \mid \kappa ; H)$ is lower than $V^{\rho}\left(R, \hat{p}^{\rho}\right)$ given by the horizontal solid line, which provides a graphical representation that the revolution constraint is a necessary condition for the commitment problem. $\widetilde{V}^{\rho}(E \mid \kappa ; H)$ slopes upwards from this point because an increase in $\kappa$ increases the expected number of periods in the future for which the elite set $\hat{p}^{\rho}$ as opposed to $\hat{p}^{\varepsilon}$. If $\kappa=1$ then the elite set $p_{t}^{\varepsilon}=\hat{p}^{\rho}$ in every period in the future, inducing the same level of welfare as democracy via an extension of the franchise. Given this structure, there must exist a value, $\bar{\kappa}$, at which $\widetilde{V}^{\rho}(E \mid \kappa ; H)=V^{\rho}\left(R, \hat{p}^{\rho}\right)$. Note that $\bar{\kappa} \rightarrow 1$ as $\psi \rightarrow 1$.

Now consider the elite's options in state $H$. For $\kappa>\bar{\kappa}$, it is feasible for the elite to use trade policy to maintain the status quo because they can feasibly induce a level of welfare in the rest of society that is at least as great as from revolution: $\tilde{V}^{\rho}(E \mid \kappa ; H)>V^{\rho}\left(R, \hat{p}^{\rho}\right)$ over this range. This is based on the fact that the expected number of periods in the future for which the elite can set $\hat{p}^{\rho}$ as opposed to $\hat{p}^{\varepsilon}$ is sufficiently large. For $\kappa<\bar{\kappa}, \widetilde{V}^{\rho}(E \mid \kappa ; H)<V^{\rho}\left(R, \hat{p}^{\rho}\right)$ because the expected number of periods in the future for which the elite can set $\hat{p}^{\rho}$ is not sufficiently large. So in this case the elite do face a commitment problem, and must extend the franchise in order to defuse the threat of revolution. 
Having established the range of $\kappa$ for which it is feasible for the elite to use trade policy to maintain the status quo, we will now examine the trade policy that the elite actually set in equilibrium, by providing a characterization of $p^{s}$. Letting $p^{\varepsilon}=\hat{p}^{\varepsilon}$ in (18), $G\left(\hat{p}^{\varepsilon}\right)<0$ by the revolution constraint. Therefore, if a value $p^{s}$ exists such that $G\left(p^{s}\right)=0$, it must be because the payoff in the current period under $p^{s}$ is $W^{\rho}\left(p^{s}, Y^{\rho}\left(p^{s}\right)\right)>W^{\rho}\left(\hat{p}^{\varepsilon}, Y^{\rho}\left(\hat{p}^{\varepsilon}\right)\right)$. And by the optimality of the choice of $\hat{p}^{\rho}$, it must be the case that $W^{\rho}\left(\hat{p}^{\rho}, Y^{\rho}\left(\hat{p}^{\rho}\right)\right)>W^{\rho}\left(p^{s}, Y^{\rho}\left(p^{s}\right)\right)$. Putting these observations together, $W^{\rho}\left(\hat{p}^{\rho}, Y^{\rho}\left(\hat{p}^{\rho}\right)\right)>W^{\rho}\left(p^{s}, Y^{\rho}\left(p^{s}\right)\right)>W^{\rho}\left(\hat{p}^{\varepsilon}, Y^{\rho}\left(\hat{p}^{\varepsilon}\right)\right)$. It also follows, by the fact that $\hat{p}^{\varepsilon}>\hat{p}^{\rho}$ and the concavity of $W^{j}\left(p_{t}, Y^{j}\left(p_{t}\right)\right)$, that $\hat{p}^{\varepsilon}>p^{s}>\hat{p}^{\rho}$. Note, again by the concavity of $W^{j}\left(p_{t}, Y^{j}\left(p_{t}\right)\right)$, that there is another value of $p_{t}$ that would yield the same level of welfare for $\rho$ as $p^{s}$, but the elite would never choose this because it is even further away from $\hat{p}^{\varepsilon}$ than $\hat{p}^{\rho}$. We can therefore also say that $W^{\varepsilon}\left(\hat{p}^{\varepsilon}, Y^{\varepsilon}\left(\hat{p}^{\varepsilon}\right)\right)>W^{\varepsilon}\left(p^{s}, Y^{\varepsilon}\left(p^{s}\right)\right)>$ $W^{\varepsilon}\left(\hat{p}^{\rho}, Y^{\varepsilon}\left(\hat{p}^{\rho}\right)\right)$.

The final step is to prove that a value of $p^{s}$ exists such that $G\left(p^{s}\right)=0$. Recall that, by definition, $G\left(\hat{p}^{\rho}\right)=0$ at $\bar{\kappa}$. And by inspection of $(17), V^{\rho}\left(E, p^{s} ; H\right)$ is increasing in $\kappa$ for given $p^{s}$. So $G\left(\hat{p}^{\rho}\right)>0$ for $\kappa>\bar{\kappa}$ and, by concavity of $W^{\rho}\left(p_{t}, Y^{\rho}\left(p_{t}\right)\right)$ in $p_{t}$, there must exist a unique value of $p^{s}>\hat{p}^{\rho}$ at which $G\left(p^{s}\right)=0$. Moreover, $p^{s}$ increases continuously as $\kappa$ is increased. But it cannot reach $\hat{p}^{\varepsilon}$ by the fact that the revolution constraint is binding. So there must exist a value of $p^{s}$ for which $\hat{p}^{\varepsilon}>p^{s}>\hat{p}^{\rho}$. We have now proved the following result:

Proposition 3. Assume a value of $\beta$ sufficiently high that the revolution constraint binds. For $\kappa>\bar{\kappa}$, there exists a unique status quo price, $p^{s}$, that entails a compromise between the two groups in the sense that: (i) $\hat{p}^{\varepsilon}>p^{s}>\hat{p}^{\rho}$; (ii) $W^{\rho}\left(\hat{p}^{\rho}, Y^{\rho}\left(\hat{p}^{\rho}\right)\right)>W^{\rho}\left(p^{s}, Y^{\rho}\left(p^{s}\right)\right)>$ $W^{\rho}\left(\hat{p}^{\varepsilon}, Y^{\rho}\left(\hat{p}^{\varepsilon}\right)\right)$; and (iii) $W^{\varepsilon}\left(\hat{p}^{\varepsilon}, Y^{\varepsilon}\left(\hat{p}^{\varepsilon}\right)\right)>W^{\varepsilon}\left(p^{s}, Y^{\varepsilon}\left(p^{s}\right)\right)>W^{\varepsilon}\left(\hat{p}^{\rho}, Y^{\varepsilon}\left(\hat{p}^{\rho}\right)\right)$.

With our characterization of the status quo price in hand, we can we can now characterize equilibrium.

Proposition 4. Assume a value of $\beta$ sufficiently high that the revolution constraint binds. For $\kappa \neq \bar{\kappa}$ there exists a unique pure strategy Markov Perfect Equilibrium with the following characteristics.

(i) If $\kappa<\bar{\kappa}$ then the elite will respond to the threat of revolution by extending the franchise.

(ii) If $\kappa>\bar{\kappa}$ then in response to the threat of revolution the elite will temporarily raise the rest of society's welfare by setting the status quo price using trade policy. 
A full formal statement and proof of Proposition 4 is presented in Appendix A.4. We have already seen in the discussion of Lemma 1 that for $\kappa<\bar{\kappa}$ the elite face a commitment problem and so must extend the franchise, while for $\kappa>\bar{\kappa}$ they can induce a higher level of expected welfare than the rest of society could obtain from revolution by setting $\hat{p}^{\rho}$. But to maintain the status quo, the elite only have to set trade policy to equalize the level of expected welfare that the rest of society would obtain under revolution. Therefore, $p^{s}$ induces a level of expected welfare that is exactly equal to revolution, given by the solid horizontal line to the right of $\bar{\kappa}$. It follows that the higher the value of $\kappa$ above $\bar{\kappa}$, the closer $p^{s}$ can be to $\hat{p}^{\varepsilon}$ and still induce a level of expected welfare for the rest of society equivalent to revolution. This also implies that, as $\kappa$ approaches $\bar{\kappa}$ from above, $p^{s}$ must converge to $\hat{p}^{\rho}$ from above. ${ }^{29}$

Building on Proposition 4, we can now characterize in more detail the relationship between democratization, trade liberalization and economic efficiency. By the Stolper-Samuelson Theorem, owners of the scarce factor seek a relatively closed trade regime. If the country has a comparative advantage in good $\rho$ then elite rule will entail a relatively closed trade regime while democracy will entail a relatively open regime. The converse preference over openness will hold across the groups if the country has a comparative advantage in good $\varepsilon$. These observations can be combined with Proposition 4 in a straight forward way to yield the following result.

Proposition 5. Consider the equilibrium characterized in Proposition 4.

(i) If $\kappa<\bar{\kappa}$ and the country has a comparative advantage in good $\varepsilon$ (good $\rho$ ) then under elite rule the trade regime is relatively open (closed). Then the threat of revolution is met by extension of the franchise, trade protectionism (liberalization), and a decrease (increase) in economic efficiency.

(ii) If $\kappa>\bar{\kappa}$ then the elite will temporarily raise the rest of society's welfare using trade policy in response to the threat of revolution. If the country has a comparative advantage in good $\varepsilon$ (good $\rho$ ) then this involves temporary trade protectionism (trade liberalization) and a correspondingly temporary decrease (increase) in economic efficiency.

Proposition 5(i) shows that quite a stringent set of conditions is required for democratization to

\footnotetext{
${ }^{29}$ In this deterministic, perfect information environment there are no revolutions on the equilibrium path. One way for revolution to occur in equilibrium is if there is some uncertainty over whether or not the rest of society can resolve their coordination problem. This uncertainty would make a risk-neutral elite less generous towards the rest of society in their setting of $p^{s}$, meaning that the elite would do better when coordination fails but worse when it doesn't. Otherwise the basic logic of the policy choice would be the same.
} 
go hand in hand with trade liberalization and a corresponding increase in economic efficiency, as advocated by Smith (1776): the probability that the rest of society will resolve their coordination problem must be low, and the elite must own the scarce factor. Indeed, if the elite own the relatively abundant factor then democratization will entail retrenchment to a relatively protectionist regime and a reduction in efficiency. Moreover, Proposition 5(ii) shows that if the opportunity to mount a revolution arises relatively frequently, the elite will actually use trade liberalization to forestall democratization. It is in these respects that the conditions under which a ruling elite can be expected to follow classical liberal advocations are quite stringent.

\section{Dictatorial Trade Policy Responses to Permanent World Price Shocks}

We will now undertake comparative statics on the equilibrium characterized in Proposition 5, with a specific focus on the policy response to a permanent world price shock. For the purposes of this exercise, we will restrict the parameter space to the region where $\kappa>\bar{\kappa}$. This puts us in the range where equilibrium is characterized by Proposition 5(ii). In this range, if $s=H$ then the elite do not face a commitment problem. By restricting parameters in this way, we will be able to focus on the way that a shock to $p^{w}$ affects $p^{s}$ and hence trade policy.

If a shock to $p^{w}$ makes revolution more attractive to the rest of society, then the elite must adjust $p^{s}$ so as to increase the payoff to the rest of society from maintaining the status quo. If a shock to $p^{w}$ makes revolution less attractive, the elite can adjust $p^{s}$ to raise their own payoff at the rest of society's expense. Formally, the relationship between $p^{w}$ and $p^{s}$ is given by:

$$
\frac{\partial p^{s}}{\partial p^{w}}=-\frac{\partial G\left(p^{s} ; p^{w}\right) / \partial p^{w}}{\partial G\left(p^{s} ; p^{w}\right) / \partial p^{s}}
$$

where here we write $G(\cdot)$ to show its dependence on $p^{w}$.

To use the model structure that we have developed above to sign $\partial p^{s} / \partial p^{w}$, we can equivalently evaluate $\partial p^{s} / \partial p^{w}$ using the following:

$$
\begin{aligned}
\frac{d W^{\rho}\left(p^{s}, Y^{\rho}\left(p^{s}\right)\right)}{d p^{w}}= & \frac{1-\beta}{1-\beta(1-\kappa)} \frac{d W^{\rho}\left(\hat{p}^{\rho}, Y_{R}^{\rho}\left(\hat{p}^{\rho}\right)\right)}{d p^{w}}+\frac{\beta}{1-\beta(1-\kappa)} \frac{d W^{\rho}\left(\hat{p}^{\rho}, Y^{\rho}\left(\hat{p}^{\rho}\right)\right)}{d p^{w}} \\
& -\frac{\beta(1-\kappa)}{1-\beta(1-\kappa)} \frac{d W^{\rho}\left(\hat{p}^{\varepsilon}, Y^{\rho}\left(\hat{p}^{\varepsilon}\right)\right)}{d p^{w}}
\end{aligned}
$$

where

$$
\frac{d W^{\rho}\left(p^{s}, Y^{\rho}\left(p^{s}\right)\right)}{d p^{w}}=\frac{\partial W^{\rho}\left(p^{s}, Y^{\rho}\left(p^{s}\right)\right)}{\partial p^{w}}+\frac{\partial W^{\rho}\left(p^{s}, Y^{\rho}\left(p^{s}\right)\right)}{\partial p^{s}} \frac{\partial p^{s}}{\partial p^{w}},
$$




$$
\begin{aligned}
& \frac{d W^{\rho}\left(\hat{p}^{\rho}, Y_{R}^{\rho}\left(\hat{p}^{\rho}\right)\right)}{d p^{w}}=\frac{\partial W^{\rho}\left(\hat{p}^{\rho}, Y_{R}^{\rho}\left(\hat{p}^{\rho}\right)\right)}{\partial p^{w}}+\frac{\partial W^{\rho}\left(\hat{p}^{\rho}, Y_{R}^{\rho}\left(\hat{p}^{\rho}\right)\right)}{\partial \hat{p}^{\rho}} \frac{\partial \hat{p}^{\rho}}{\partial p^{w}} \\
& \frac{d W^{\rho}\left(\hat{p}^{\rho}, Y^{\rho}\left(\hat{p}^{\rho}\right)\right)}{d p^{w}}=\frac{\partial W^{\rho}\left(\hat{p}^{\rho}, Y^{\rho}\left(\hat{p}^{\rho}\right)\right)}{\partial p^{w}}+\frac{\partial W^{\rho}\left(\hat{p}^{\rho}, Y^{\rho}\left(\hat{p}^{\rho}\right)\right)}{\partial \hat{p}^{\rho}} \frac{\partial \hat{p}^{\rho}}{\partial p^{w}}
\end{aligned}
$$

and

$$
\frac{d W^{\rho}\left(\hat{p}^{\varepsilon}, Y^{\rho}\left(\hat{p}^{\varepsilon}\right)\right)}{d p^{w}}=\underbrace{\frac{\partial W^{\rho}\left(\hat{p}^{\varepsilon}, Y^{\rho}\left(\hat{p}^{\varepsilon}\right)\right)}{\partial p^{w}}}_{\text {Direct effect }}+\underbrace{\frac{\partial W^{\rho}\left(\hat{p}^{\varepsilon}, Y^{\rho}\left(\hat{p}^{\varepsilon}\right)\right)}{\partial \hat{p}^{\varepsilon}} \frac{\partial \hat{p}^{\varepsilon}}{\partial p^{w}}}_{\text {Indirect effect }} .
$$

Equation (20) is obtained by using (14) and (17) in (18), where $p^{\varepsilon}=p^{s}$ so that $G\left(p^{s} ; p^{w}\right)=0$, then differentiating the resulting expression with respect to $p^{w}$ and rearranging. Expanding out the left hand side of (20) as shown in (21), we see that $\partial p^{s} / \partial p^{w}$ is in the final term.

From equations (21) to (24), we can see that there are two effects through which a change in $p^{w}$ must influence $p^{s}$ via (20). One is through the 'direct' effect of a change in $p^{w}$ on $Y^{\rho}\left(p_{t}\right)$ and hence $W^{\rho}\left(\hat{p}^{\varepsilon}, Y^{\rho}\left(\hat{p}^{\varepsilon}\right)\right), W^{\rho}\left(\hat{p}^{\rho}, Y^{\rho}\left(\hat{p}^{\rho}\right)\right)$ and $W^{\rho}\left(p^{s}, Y^{\rho}\left(p^{s}\right)\right)$. The other is through the 'indirect' effects whereby a change in $p^{w}$ affects $\hat{p}^{\varepsilon}$ and $\hat{p}^{\rho}$.

Equations (22) and (23) capture the effect of a shock to $p^{w}$ on the rest of society's payoff to revolution (followed by democracy), while (24) captures the effect on their payoff to maintaining the status quo. From (20), the sign of $d W^{\rho}\left(p^{s}, Y^{\rho}\left(p^{s}\right)\right) / d p^{w}$ (and hence $\partial p^{s} / \partial p^{w}$ ) is clear cut if these effects have opposite signs. But as we shall see, they may have the same signs, in which case the sign of $d W^{\rho}\left(p^{s}, Y^{\rho}\left(p^{s}\right)\right) / d p^{w}$ is ambiguous. The direct and indirect effects are given by the first and second terms respectively of equations (22)-(24). We will take each in turn, starting with the indirect effects because the analysis will also be helpful in determining the direct effects. (We will discuss the direct and indirect effects for (21) in due course.)

To obtain the indirect effects, we need to sign $\partial \hat{p}^{\varepsilon} / \partial p^{w}$ and $\partial \hat{p}^{\rho} / \partial p^{w}$, and to do this we need to return to group $j$ 's preferred price problem as given by (8). We can ascertain the effect of a change in $p^{w}$ on $\hat{p}^{j}$ by differentiating (8) with respect to $p^{w}$ :

$$
\begin{aligned}
\frac{d f o c_{t}^{j}}{d p^{w}}= & \frac{\partial W_{t}^{j}}{\partial Y_{t}^{j}} \phi^{j}\left(p_{t}\right)\left(-\frac{\partial m_{t}}{\partial p_{t}}+\left(p_{t}-p^{w}\right) \frac{\partial^{2} m_{t}}{\partial p_{t} \partial p^{w}}\right) \\
& +\frac{\partial W_{t}^{j}}{\partial Y_{t}^{j}} \frac{\partial Y_{t}}{\partial p^{w}} \frac{\partial \phi_{t}^{j}}{\partial p_{t}} .
\end{aligned}
$$

If the right hand side of this expression is positive then an increase in $p^{w}$ brings about an increase in $\hat{p}^{j}$; if it is negative then the effect on $\hat{p}^{j}$ is the opposite. Recall from the discussion following (8) that $f o c^{j}\left(p_{t}\right)$ is determined by two effects: $j$ 's distortion share and the Stolper-Samuelson 
effect on $j$. The first line on the right hand side of (25) captures how a shock to $p^{w}$ affects $j$ 's distortion share and the second line captures how the shock to $p^{w}$ changes the Stolper-Samuelson effect on $j$. We will take each of these in turn.

First recall that, under the assumptions we have already made, $\partial W_{t}^{j} / \partial Y_{t}^{j}>0$ for all $Y_{t}^{j} \geq 0$. Also, the first term in brackets on the first line, $-\partial m_{t} / \partial p_{t}$, is positive whether the country's comparative advantage is in $\operatorname{good} \varepsilon$ or good $\rho$. Economic theory does not impose any conditions on the sign of the second-cross-partial derivative in the second term. However, it is reasonable to assume that, being of second order, it will be smaller than the first term. We will assume this to be the case throughout our analysis. ${ }^{30}$ Whether we think of this effect in terms of $j$ 's distortion share, or a price effect, the impact of a positive shock to $p^{w}$ on both $\hat{p}^{\varepsilon}$ and $\hat{p}^{\rho}$ would unambiguously be positive. If there were only an impact through this channel, as under quasi-linear preferences for example, then the impact of $p^{w}$ on both $\hat{p}^{\varepsilon}$ and $\hat{p}^{\rho}$ would unambiguously be positive.

Regarding the term on the second line, which captures the 'Stolper-Samuelson' or 'income' effect on $j$, we have already established from (10) and (11) that $\partial \phi_{t}^{\varepsilon} / \partial p_{t}>0$ and $\partial \phi_{t}^{\rho} / \partial p_{t}<0$. The final step is to evaluate the sign of $\partial Y_{t} / \partial p^{w}$. From (4) and (5):

$$
\frac{\partial Y_{t}}{\partial p^{w}}=-\frac{1}{1-\left(p_{t}-p^{w}\right) c_{\varepsilon}\left(p_{t}\right)} m_{t} .
$$

At free trade (i.e. for $p_{t}=p^{w}$ ), we see that this expression captures the standard effect whereby an increase in a country's terms-of-trade improves national income. Accordingly, if the country has a comparative advantage in good $\varepsilon$ and $p_{t}=p^{w}$ then in a trading equilibrium $m_{t}<0$ and $\partial Y_{t} / \partial p^{w}>0$. What about if $p_{t}>p^{w}$ ? Given $\left(p_{t}-p^{w}\right) c_{\varepsilon}\left(p_{t}\right)<1$, the coefficient on $m_{t}$ in (26) is unambiguously negative. If $p_{t}<p^{w}$ then this is immediate. Therefore, $\partial Y_{t} / \partial p^{w}>$ 0 and hence $\partial W_{t}^{j} / \partial Y_{t}^{j} \cdot \partial Y_{t} / \partial p^{w}>0$ if the country has a comparative advantage in good $\varepsilon$. Use this to consider the effect of a positive shock to $p^{w}$ on $\hat{p}^{\varepsilon}$ when the country has a comparative advantage in good $\varepsilon$. Since $\partial \phi_{t}^{\varepsilon} / \partial p_{t}>0$, the Stolpher-Samuelson/income effect $\partial W_{t}^{\varepsilon} / \partial Y_{t}^{\varepsilon} \cdot \partial Y_{t} / \partial p^{w} \cdot \partial \phi_{t}^{\varepsilon} / \partial p_{t}>0$, and works in the same direction as the distortion share/price effect. Therefore, with a comparative advantage in good $\varepsilon$, the effect of a positive shock to $p^{w}$ on $\hat{p}^{\varepsilon}$ is unambiguously positive. The same is true for the effect of a shock to $p^{w}$ on $\hat{p}^{\rho}$ with a comparative advantage in good $\rho$. While $\partial W_{t}^{j} / \partial Y_{t}^{j} \cdot \partial Y_{t} / \partial p^{w}<0$ because $m_{t}>0$ in (26) this

\footnotetext{
${ }^{30}$ This assumption can be demonstrated to hold for all admissible parameter values of the constant elasticity of substitution (C.E.S.) example that we develop in Appendix A.5.
} 
time, we alternatively have $\partial \phi_{t}^{\rho} / \partial p_{t}<0$. And so again the income effect is positive, and works in the same direction as the price effect.

It is now straight forward to see that ambiguities will arise for the other two cases: a shock to $p^{w}$ on $\hat{p}^{\rho}$ with a comparative advantage in good $\varepsilon$ or on $\hat{p}^{\varepsilon}$ with a comparative advantage in $\operatorname{good} \rho$. The reason for the ambiguity is that the impact through the income effect channel is negative, and operates in the opposite direction to impact through the price effect channel. For a comparative advantage in good $\varepsilon, \partial W_{t}^{\varepsilon} / \partial Y_{t}^{\varepsilon} \cdot \partial Y_{t} / \partial p^{w} \cdot \partial \phi_{t}^{\rho} / \partial p_{t}<0$, and similarly for a comparative advantage in good $\rho, \partial W_{t}^{\rho} / \partial Y_{t}^{\rho} \cdot \partial Y_{t} / \partial p^{w} \cdot \partial \phi_{t}^{\varepsilon} / \partial p_{t}<0 .{ }^{31}$ Let us summarize the preceding discussion as follows. ${ }^{32}$

Lemma 2. (i) Assume a comparative advantage in good $\varepsilon$, so $p^{a} \leq \hat{p}^{\rho}<p^{w} \leq \hat{p}^{\varepsilon}$. Then a positive shock to $p^{w}$ unambiguously increases $\hat{p}^{\varepsilon}$; if $\hat{p}^{\rho}$ is at an interior solution $p^{a}<\hat{p}^{\rho}$, the effect on $\hat{p}^{\rho}$ is ambiguous and corresponds to the sign of (25); if in the absence of domestic fiscal capacity $\hat{p}^{\rho}$ is at a corner solution, $p^{a}=\hat{p}^{\rho}$, then a shock to $p^{w}$ has no effect on $\hat{p}^{\rho}$.

(ii) Assume a comparative advantage in $\operatorname{good} \rho$, so $\hat{p}^{\rho} \leq p^{w}<\hat{p}^{\varepsilon} \leq p^{a}$. Then a positive shock to $p^{w}$ unambiguously increases $\hat{p}^{\rho}$; if $\hat{p}^{\varepsilon}$ is at an interior solution $\hat{p}^{\varepsilon}<p^{a}$, the effect on $\hat{p}^{\varepsilon}$ is ambiguous and corresponds to the sign of (25); if in the absence of domestic fiscal capacity $\hat{p}^{\varepsilon}$ is at a corner solution, $\hat{p}^{\varepsilon}=p^{a}$, then a shock to $p^{w}$ has no effect on $\hat{p}^{\varepsilon}$.

Summarizing the indirect effect, Lemma 2 has established that there is an ambiguity over the sign of $\partial \hat{p}^{\rho} / \partial p^{w}$ when the comparative advantage is in good $\varepsilon$ and $\partial \hat{p}^{\varepsilon} / \partial p^{w}$ when the comparative advantage is in good $\rho$, and in these cases there is an ambiguity in the indirect effect; otherwise, away from corner solutions involving autarky, $p^{a}, \partial \hat{p}^{j} / \partial p^{w}$ is positive. To consider systematically the implications for signing (20), and hence $\partial p^{s} / \partial p^{w}$, it will be useful to partition the analysis by comparative advantage. In the next subsection, we will consider arguably the more familiar case, in which the country has a comparative advantage in good $\rho$, so the trade policy instrument applied to good $\varepsilon$ is an import tariff. In the subsection following that we will consider the case where the country has a comparative advantage in good $\varepsilon$, and the trade policy instrument applied to good $\varepsilon$ is an export tax.

It remains to sign the direct effect, $\partial W^{\rho}\left(\hat{p}^{j}, Y^{\rho}\left(\hat{p}^{j}\right)\right) / \partial p^{w}=\partial W^{\rho}\left(\hat{p}^{j}, Y^{\rho}\left(\hat{p}^{j}\right)\right) / \partial Y_{t}^{j} \times$ $\partial Y_{t}^{j} / \partial p^{w}$, which is determined by (26). If the country has a comparative advantage in good $\varepsilon$

\footnotetext{
${ }^{31}$ In Appendix A.5 we illustrate this ambiguity using our C.E.S. example.

${ }^{32}$ See Appendix A.4 for a proof.
} 
then $\partial W^{\rho}\left(\hat{p}^{j}, Y^{\rho}\left(\hat{p}^{j}\right)\right) / \partial p^{w}>0$ because $\partial Y_{t}^{j} / \partial p^{w}>0$; if the comparative advantage is in good $\rho$ then $\partial W^{\rho}\left(\hat{p}^{j}, Y^{\rho}\left(\hat{p}^{j}\right)\right) / \partial p^{w}<0$ because $\partial Y_{t}^{j} / \partial p^{w}<0, j \in\{\varepsilon, \rho\} .{ }^{33}$

\subsection{Response to World Price Shock with Comparative Advantage in Good $\rho$}

With a comparative advantage in good $\rho, \hat{p}^{\rho} \leq p^{w}<\hat{p}^{\varepsilon} \leq p^{a}$. Throughout this subsection, we will focus our discussion on the situation where there is no fiscal capacity, and so $\hat{p}^{\rho}=p^{w}$, while $p^{w}<\hat{p}^{\varepsilon} \leq p^{a}$ by Proposition 1(ii). This will not have a qualitative impact on our results, as will be made clear where relevant.

Look first at (22) and (23). With a comparative advantage in good $\rho$, the direct effect is negative. Regarding the indirect effect, since $\hat{p}^{\rho}=p^{w}$ is a corner solution it is immediate that $\partial \hat{p}^{\rho} / \partial p^{w}>0$. And since $\hat{p}^{\rho}$ is constrained above its optimum level, $\partial W^{\rho}\left(\hat{p}^{\rho}, Y_{R}^{\rho}\left(\hat{p}^{\rho}\right)\right) / \partial \hat{p}^{\rho}<0$. Therefore the indirect effect is negative as well, and so, by $(22), d W^{\rho}\left(\hat{p}^{\rho}, Y_{R}^{\rho}\left(\hat{p}^{\rho}\right)\right) / d p^{w}<0 .{ }^{34}$ Exactly the same properties hold for $(23)$ and so $d W^{\rho}\left(\hat{p}^{\rho}, Y^{\rho}\left(\hat{p}^{\rho}\right)\right) / d p^{w}<0$ as well. Therefore, the effect of a shock to $p^{w}$ is to reduce the rest of society's payoff to revolution.

Turning to $d W^{\rho}\left(\hat{p}^{\varepsilon}, Y^{\rho}\left(\hat{p}^{\varepsilon}\right)\right) / d p^{w}$, we see that its sign is ambiguous. The direct effect is negative: $\partial W^{\rho}\left(\hat{p}^{\varepsilon}, Y^{\rho}\left(\hat{p}^{\varepsilon}\right)\right) / \partial p^{w}<0$, as it was for (22) and (23). Regarding the indirect effect, we know that $\partial W^{\rho}\left(\hat{p}^{\varepsilon}, Y^{\rho}\left(\hat{p}^{\varepsilon}\right)\right) / \partial \hat{p}^{\varepsilon}<0$ by $\hat{p}^{\varepsilon}>\hat{p}^{\rho}$ and the concavity of $W^{\rho}\left(p_{t}, Y^{\rho}\left(p_{t}\right)\right)$. So the ambiguity all comes down to the ambiguity over the sign of $\partial \hat{p}^{\varepsilon} / \partial p^{w}$ identified in Lemma 2. If $\partial \hat{p}^{\varepsilon} / \partial p^{w}<0$ then the indirect effect is positive, and if it is larger than the direct effect then $d W^{\rho}\left(\hat{p}^{\varepsilon}, Y^{\rho}\left(\hat{p}^{\varepsilon}\right)\right) / d p^{w}>0$ and $d W^{\rho}\left(p^{s}, Y^{\rho}\left(p^{s}\right)\right) / d p^{w}<0$. But if the indirect effect is smaller than the direct effect, or if $\partial \hat{p}^{\varepsilon} / \partial p^{w}>0$, then $d W^{\rho}\left(\hat{p}^{\varepsilon}, Y^{\rho}\left(\hat{p}^{\varepsilon}\right)\right) / d p^{w}<0$ and the sign of $d W^{\rho}\left(p^{s}, Y^{\rho}\left(p^{s}\right)\right) / d p^{w}$ is ambiguous. Therefore, there is an ambiguity in the effect of a shock to $p^{w}$ on the rest of society's payoff to maintaining the status quo.

A simple way to resolve this ambiguity is by putting a lower bound on $\kappa$. Looking at $(20)$, we can see that the coefficients on the three terms on the right hand side are all monotonically decreasing in $\kappa$. But the coefficient on the third term $d W^{\rho}\left(\hat{p}^{\varepsilon}, Y^{\rho}\left(\hat{p}^{\varepsilon}\right)\right) / d p^{w}$, the sign of which we have just seen is ambiguous, decreases more quickly than the other two and eventually goes

\footnotetext{
${ }^{33} \mathrm{By}(6), Y_{t}^{j}=\phi_{t}^{j} Y_{t}$ and so $\partial Y_{t}^{j} / \partial p^{w}=\phi_{t}^{j} \partial Y_{t} / \partial p^{w} ; \phi_{t}^{j}$ as determined by (1) is unaffected by a change in $p^{w}$.

${ }^{34}$ The outcome is the same when there is domestic fiscal capacity. Then, $\hat{p}^{\rho}$ can be set at its optimal level and so $\partial W^{\rho}\left(\hat{p}^{\rho}, Y_{R}^{\rho}\left(\hat{p}^{\rho}\right)\right) / \partial \hat{p}^{\rho}=0$. Also, although it has no bearing on this case, we established in Lemma 2 that $\partial \hat{p}^{\rho} / \partial p^{w}>0$. Therefore, by $(22) d W^{\rho}\left(\hat{p}^{\rho}, Y_{R}^{\rho}\left(\hat{p}^{\rho}\right)\right) / d p^{w}<0$.
} 
to zero. ${ }^{35}$ The derivatives that appear on the right hand side of $(20)\left(d W^{\rho}\left(\hat{p}^{\rho}, Y_{R}^{\rho}\left(\hat{p}^{\rho}\right)\right) / d p^{w}\right.$ etc.) are given and do not depend on $\beta$ or $\kappa$. So we can always increase $\kappa$ to the point where the absolute magnitude of the third term is smaller than the sum of the other two. We know the sum of the first two terms is unambiguously negative. So there exists a lower bound on $\kappa$, which we will call $\widetilde{\kappa}$, above which $(20)$ must be negative. Given our restriction to the range $\kappa>\bar{\kappa}$ in this section, it must be the case that $1>\widetilde{\kappa} \geq \bar{\kappa}$. Then for any $\kappa>\widetilde{\kappa}, d W^{\rho}\left(p^{s}, Y^{\rho}\left(p^{s}\right)\right) / d p^{w}<0$ and the ambiguity is resolved.

Over the range $1>\widetilde{\kappa} \geq \bar{\kappa}$, we can now say how $p^{s}$ must be adjusted in response to a shock to $p^{w}$. To do so, consider (21). We have already established that the right hand side of (20) is negative for $\kappa>\widetilde{\kappa}$. So for this range of $\kappa$ the sum of the components on the right hand side of (21), must be negative as well. And we already know that the direct effect is negative, given a comparative advantage in good $\rho$. Providing the magnitude of the direct effect, $\partial W^{\rho}\left(p^{s}, Y^{\rho}\left(p^{s}\right)\right) / \partial p^{w}$, is smaller than the total effect, $d W^{\rho}\left(p^{s}, Y^{\rho}\left(p^{s}\right)\right) / d p^{w}$, the indirect effect must be negative as well. Since $\partial Y_{t}^{\rho} / \partial p^{w}=\phi_{t}^{\rho} \partial Y_{t} / \partial p^{w}$ is a component of the direct effect, the direct effect is sufficiently small if the rest of society's relative income share, $\phi_{t}^{\rho}$, is sufficiently small. This can be ensured by increasing the size of the elite's endowment of land relative to the labor endowment. ${ }^{36}$ This ensures in turn that the rest of society's loss of tariff revenue income through trade liberalization does not make them favor an increase in protection, reflecting the typical situation in dictatorships where the rest of society are not significant beneficiaries of tariff revenue. So for $\phi_{t}^{\rho}$ sufficiently small, the indirect effect must be negative. By the concavity of $W^{\rho}\left(p_{t}, Y^{\rho}\left(p_{t}\right)\right)$ in $p_{t}$, coupled with the fact that $\hat{p}^{\varepsilon}>p^{s}>\hat{p}^{\rho}$, we have that $\partial W^{\rho}\left(p^{s}, Y^{\rho}\left(p^{s}\right)\right) / \partial p^{s}<0$. So for the indirect effect to be negative, it must be the case that $\partial p^{s} / \partial p^{w}>0$. We will now summarize this result and then discuss its implications.

Proposition 6. Assume a comparative advantage in good $\rho$. There exists a lower bound $\widetilde{\kappa} \in[\bar{\kappa}, 1)$ for which $d W^{\rho}\left(p^{s}, Y^{\rho}\left(p^{s}\right)\right) / d p^{w}<0$ for all $\kappa>\widetilde{\kappa}$. Over this range, for $\phi_{t}^{\rho}$ sufficiently small, a positive shock to $p^{w}$ results in an increase in $p^{s}: \partial p^{s} / \partial p^{w}>0$.

The intuition for this result is similar to that for the characterization of equilibrium in Proposi-

\footnotetext{
${ }^{35}$ The first derivative of the first and second terms with respect to $\kappa$ are $-(\beta(1-\beta)) /(1-\beta(1-\kappa))^{2}$ and $-\beta^{2} /(1-\beta(1-\kappa))^{2}$ respectively, whereas for the third term it is more negative, at $-\beta /(1-\beta(1-\kappa))^{2}$.

${ }^{36}$ In our current exposition, recall that the endowments of both labor and land have been normalized to 1. Nothing would change about the underlying analysis beyond a rebalancing of income share away from the rest of society if we increased the endowment of land relative to labor.
} 
tion 4. We know that the welfare effect on the rest of society from a shock to $p^{w}$ is ambiguous in the low threat state, as given by the third term on the right hand side of (20). But with $\kappa$ sufficiently large, the welfare effect is driven by the outcome under revolution, which is not ambiguous. In other words, with $\kappa$ sufficiently large, the elite can credibly commit to respond to a shock to $p^{w}$ by adjusting $p^{s}$ in such a way that will make the rest of society better off.

We still do not have a clear cut prediction about the direction in which tariffs must be adjusted. The formula for an ad valorem tariff is $\tau=\left(p^{s}-p^{w}\right) / p^{w}$. From this we see that, to obtain a positive relationship between $p^{w}$ and $\tau$, it must be the case that $\partial p^{s} / \partial p^{w}>1$ (and not just $\left.\partial p^{s} / \partial p^{w}>0\right)$. This can be accomplished by assuming that $\psi<1$ is sufficiently large, and hence $\bar{\kappa}$ is sufficiently large. To understand the issue, look at (21). We know that the magnitude of the sum of the terms on the right hand side is given by the sum of the terms on the right hand side of $(20)$, and for $\kappa>\widetilde{\kappa}$ this must be negative. We also know that for $\phi_{t}^{\rho}$ sufficiently small, both the direct and indirect effects in (21) must be negative. For given $\kappa$, we can take $p^{s}$ and hence the direct effect $\partial W^{\rho}\left(p^{s}, Y^{\rho}\left(p^{s}\right)\right) / \partial p^{w}$ as given. So the magnitude of the indirect effect is given as well. Now if we can use the structure of the model to restrict the magnitude of $\partial W^{\rho}\left(p^{s}, Y^{\rho}\left(p^{s}\right)\right) / \partial p^{s}$, then the size of $\partial p^{s} / \partial p^{w}$ must increase correspondingly. At $\hat{p}^{\rho}, \partial W^{\rho}\left(\hat{p}^{\rho}, Y^{\rho}\left(\hat{p}^{\rho}\right)\right) / \partial \hat{p}^{\rho}=0$. And by the concavity of $W^{\rho}\left(p_{t}, Y^{\rho}\left(p_{t}\right)\right)$ in $p_{t}$, we can make $\partial W^{\rho}\left(p^{s}, Y^{\rho}\left(p^{s}\right)\right) / \partial p^{s}$ smaller by pushing $p^{s}$ closer to $\hat{p}^{\rho}$. We can achieve this by limiting the range (in equilibrium) of $p^{s}$ above $\hat{p}^{\rho}$. Recall from the discussion following Proposition 4 that as $\kappa$ approaches $\bar{\kappa}$ from above, $p^{s}$ must converge towards $\hat{p}^{\rho}$ from above. And we can restrict the range of $\kappa$ relative to $\bar{\kappa}$ by increasing $\bar{\kappa}$ through an increase in $\psi<1$. So there exists a value of $\psi<1$ sufficiently large that we must have $\partial p^{s} / \partial p^{w}>1$. Looking at this another way, the concavity of $W^{\rho}\left(p_{t}, Y^{\rho}\left(p_{t}\right)\right)$ in $p_{t}$ implies that, if $p^{s}$ is a long way from $\hat{p}^{\rho}$, the responsiveness of welfare to a change in $p^{s}$ will be large. Correspondingly, $\partial p^{s} / \partial p^{w}$ required to maintain the status quo would be small: perhaps not enough to match the change in $p^{w}$. The restriction on $\psi<1$ is sufficient to restrict $\kappa$ to a range where this cannot happen. Summarizing:

Proposition 7. Assume a comparative advantage in good $\rho$. Given $\phi_{t}^{\rho}$ sufficiently small, and $\psi<1$ sufficiently large, there exists a value of $\bar{\kappa} \in(0,1)$ (and hence $\widetilde{\kappa} \in[\bar{\kappa}, 1)$ ) sufficiently large that for $\kappa>\widetilde{\kappa} \geq \bar{\kappa}$ there is a more-than-proportional increase of $p^{s}$ in response to a shock to $p^{w}: \partial p^{s} / \partial p^{w}>1$. Consequently, the increase in $p^{s}$ required in response to a positive shock to $p^{w}$ would be brought about by an increase in the ad valorem tariff $\tau=\left(p^{s}-p^{w}\right) / p^{w}$. 
The intuition behind this result is more naturally understood in terms of a reduction in $p^{w}$. If $\kappa>\widetilde{\kappa} \geq \bar{\kappa}$ is sufficiently large, as the world price of the imported good falls, free trade becomes more valuable to the rest of society. This increases the payoff to democracy and hence to a revolution. This in turn provokes the elite to move $p^{s}$ and $\tau$ in the direction that the rest of society would like to see it go, namely towards free trade.

\subsection{Response to World Price Shock with Comparative Advantage in Good $\varepsilon$}

Consider now the case where the country has a comparative advantage in good $\varepsilon$, so that $p^{a} \leq$ $\hat{p}^{\rho}<p^{w} \leq \hat{p}^{\varepsilon}$. Recall that in this case the direct effect is positive, $\partial W^{\rho}\left(\hat{p}^{j}, Y^{\rho}\left(\hat{p}^{j}\right)\right) / \partial p^{w}>0$ for $j \in\{\varepsilon, \rho\}$, because now $\partial Y_{t} / \partial p^{w}>0$. As in Subsection 4.1, let us continue to assume that there is no fiscal capacity, and so $\hat{p}^{\varepsilon}=p^{w}$ while $p^{a} \leq \hat{p}^{\rho}<p^{w}$ by Proposition 1(i). Again, this will not have a qualitative impact on our results.

We will continue to use equations (20)-(24) to assess the impact of a positive shock to $p^{w}$ on $p^{s}$. Let us focus on the case where $\hat{p}^{\rho}$ is at an interior solution, $p^{a} \leq \hat{p}^{\rho}<p^{w}$, since the corner solution is similar. Note that, by Lemma 2, with a comparative advantage in good $\varepsilon$, it is the sign of $\partial \hat{p}^{\rho} / \partial p^{w}$ that is ambiguous. But because $\partial W^{\rho}\left(\hat{p}^{\rho}, Y_{R}^{\rho}\left(\hat{p}^{\rho}\right)\right) / \partial \hat{p}^{\rho}=0$ and $\partial W^{\rho}\left(\hat{p}^{\rho}, Y^{\rho}\left(\hat{p}^{\rho}\right)\right) / \partial \hat{p}^{\rho}=0$, the indirect effects in (22) and (23) are both zero. Therefore, the signs of (22) and (23) are both determined by the positive signs of the direct effects alone. So $d W^{\rho}\left(\hat{p}^{\rho}, Y_{R}^{\rho}\left(\hat{p}^{\rho}\right)\right) / d p^{w}>0$ and $d W^{\rho}\left(\hat{p}^{\rho}, Y^{\rho}\left(\hat{p}^{\rho}\right)\right) / d p^{w}>0 .{ }^{37}$

Turning to $d W^{\rho}\left(\hat{p}^{\varepsilon}, Y^{\rho}\left(\hat{p}^{\varepsilon}\right)\right) / d p^{w}$ as determined by (24), first note that the direct effect is positive as in the first two terms of (20). The indirect effect is negative by the concavity of $W^{\rho}\left(p_{t}, Y^{\rho}\left(p_{t}\right)\right)$ coupled with the fact that $\hat{p}^{\varepsilon}>\hat{p}^{\rho}$, plus the fact that $\partial \hat{p}^{\varepsilon} / \partial p^{w}>0$ unambiguously. ${ }^{38}$ So, as for a comparative advantage in good $\rho$, the sign of $d W^{\rho}\left(\hat{p}^{\varepsilon}, Y^{\rho}\left(\hat{p}^{\varepsilon}\right)\right) / d p^{w}$ depends on whether the direct or the indirect effect is larger. Evidently, with a comparative advantage in $\operatorname{good} \varepsilon$ the ambiguity may still arise.

Like for a comparative advantage in good $\rho$, a simple way to resolve this ambiguity is by putting a lower bound on $\kappa$. Since, again, it is the third term of (20) that introduces the

\footnotetext{
${ }^{37}$ There is no significance to the fact that the details of the analysis differ under a comparative advantage in $\operatorname{good} \varepsilon$ to good $\rho$. If we had chosen $\operatorname{good} \varepsilon$ to be the numeraire, then the indirect effects in equations (22) and (23) would have been zero for a comparative advantage in good $\rho$ instead of good $\varepsilon$.

${ }^{38}$ Even in the presence of domestic fiscal capacity, by Lemma 2(i), with a comparative advantage in good $\varepsilon$, $\partial \hat{p}^{\varepsilon} / \partial p^{w}>0$ unambiguously.
} 
ambiguity, and since the coefficient on the third term is decreasing in $\kappa$ more quickly than the first and second, we can always find a lower bound $1>\widetilde{\kappa} \geq \bar{\kappa}$ such that, for any $\kappa>\widetilde{\kappa}$, $d W^{\rho}\left(p^{s}, Y^{\rho}\left(p^{s}\right)\right) / d p^{w}>0$ and the ambiguity is resolved.

We can now say how $p^{s}$ must be adjusted in response to a shock to $p^{w}$. Once again, we can use (21). We know that, for $\kappa>\widetilde{\kappa}$, the sum of the terms on the right hand side of (20) must be positive. So the total effect, given by the sum of the direct effect and the indirect effect in (21), must be as well. We already know that, given a comparative advantage in good $\rho$, the direct effect is positive. Once again, $\phi_{t}^{\rho}$ must be sufficiently small for the direct effect not to be larger than the total effect. Then the indirect effect must be positive. And once again by the concavity of $W^{\rho}\left(p_{t}, Y^{\rho}\left(p_{t}\right)\right)$ in $p_{t}$, coupled with the fact that $\hat{p}^{\varepsilon}>p^{s}>\hat{p}^{\rho}$ and $\partial W^{\rho}\left(\hat{p}^{\rho}, Y^{\rho}\left(\hat{p}^{\rho}\right)\right) / \partial \hat{p}^{\rho}=0$, we have that $\partial W^{\rho}\left(p^{s}, Y^{\rho}\left(p^{s}\right)\right) / \partial p^{s}<0$. In order for the indirect effect to be positive, it must therefore be the case that $\partial p^{s} / \partial p^{w}<0$. This means that a positive shock to $p^{w}$ must bring about a reduction in $p^{s}$ : the opposite to when there is a comparative advantage in good $\rho$.

The equation for an ad valorem export tax, $\tau^{e x}$, is $\tau^{e x}=\left(p^{s}-p^{w}\right) / p^{w}$, where $p^{s}<p^{w}$ so that $\tau^{e x}$ is negative. The fact that $p^{s}$ responds to a shock to $p^{w}$ by moving in the opposite direction takes away the need for the response of $p^{s}$ to $p^{w}$ to be sufficiently large. Therefore, for $\kappa>\widetilde{\kappa}$, any positive shock to $p^{w}$ will unambiguously lead to an increase in the size of the export tax. The analysis is summarized in the following result.

Proposition 8. Assume a comparative advantage in good $\varepsilon$. For $\phi_{t}^{\rho}$ sufficiently small, there exists a lower bound $\widetilde{\kappa} \in[\bar{\kappa}, 1]$ for which $d W^{\rho}\left(p^{s}, Y^{\rho}\left(p^{s}\right)\right) / d p^{w}>0$ for all $\kappa>\widetilde{\kappa}$. Over this range, a positive shock to $p^{w}$ results in a decrease in $p^{s}$, and this would be brought about by an increase in the size of the ad valorem export tax $\tau^{e x}=\left(p^{s}-p^{w}\right) / p^{w}$.

As the world price of the export rises, free trade becomes more appealing to the elite. But the rest of society would in this case prefer the economy to remain protectionist. So an increase in $p^{w}$ would increase the payoff to democracy, and hence to a revolution. This in turn provokes the elite to move $p^{s}$ and $\tau^{e x}$ in the direction that the rest of society would like to see it go, in this case towards autarky. 


\section{$5 \quad$ Linking 19th Century British and Prussian Trade Policy}

The differing trade policy outcomes motivated by Propositions 7 and 8 would be driven simultaneously by a common technology shock that resulted from an improvement in transport technology and a fall in transport costs. Such a fall in transport costs would simultaneously reduce $p^{w}$ as viewed from the country with a comparative advantage in good $\rho$ while increasing $p^{w}$ as viewed from the country with a comparative advantage in $\varepsilon$. In the country with a comparative advantage in good $\rho$, the response would be to reduce the tariff while the country with a comparative advantage in good $\varepsilon$ would increase its export tax.

The extended discussion of historical trade policy episodes in Appendix B provides detailed evidence to suggest that Proposition 7 predicts British trade policy from 1815-1846 while Proposition 8 predicts the trade policy experience in Prussia over the same period. Summarizing, from the perspective of 19th Century Europe, a permanent fall in the world price of grain and other food stuffs was brought about by 'the amazing decline in international transport costs' which facilitated imports from the New World (O'Rourke and Williamson 1999: 33). This provided a plausibly exogenous technological impetus to observed permanent changes in world prices and hence trade policy. Britain's comparative advantage in manufactures can be associated with a comparative advantage in good $\rho$ in our framework. In response to the fall in grain prices, Britain reduced its import tariff on grain from 70 percent in 1815 to free trade in 1846 . Prussia had a comparative advantage in good $\varepsilon$, in this case grain, and adopted the most liberal trade regime in Europe' at the end of the Napoleonic wars in 1815. But Prussia progressively increased protectionism, (both through tariffs and export taxes) over the same period (Kindleberger 1975). To obtain this prediction from our model, we also have to assume that a high threat state was maintained for a protracted period in both countries. The historical evidence provided in Appendix B does indeed suggest that the period from the end of the Napoleonic wars through to the middle of the 19th Century was among the most tumultuous in European history. Reflecting this in our framework, it seems reasonable to argue that a high threat state was maintained throughout the period 1815-1846. Under this assumption, our framework can explain the observed divergence in trade policy responses between Britain and Prussia in terms of a common technology-driven world price shock. This divergence cannot be explained by standard political economy models such as Grossman and Helpman (1994), which would predict that trade policy in both countries would have moved in the same direction in response to the shock. 


\section{Conclusions}

It is generally agreed that democratization and trade liberalization are beneficial from a normative perspective. But we have seen in this paper that the conditions under which those with the power to democratize and liberalize might actually be expected to do so are quite stringent. Not only must the ruling elite own the relatively scarce factor, but the opportunity to mount a revolution must arise infrequently as well. If the elite own the abundant factor and democratization does take place, then the trade policy adopted by the newly formed democratic government will be more protectionist than that under elite rule and, all else equal, efficiency will be reduced. The paper also characterized a set of circumstances under which the ruling elite could use trade policy to forestall democratization. The dynamics of this equilibrium outcome were then illustrated in terms of the improvements in transportation technology throughout the early 19th Century. It appears that the predictions of the model were borne out in policy practice over the period and these actions would not have been predicted by standard political economy models.

This paper opens the door to three main areas of research. Let us close by briefly discussing the scope for future research in each of these areas in turn. First, there is mounting empirical evidence in support for the 'threat of revolution' hypothesis as an explanation for extension of the franchise: see Aidt and Jensen (2014) and the references therein. This literature finds evidence that occasions when democratic transitions actually occurred were precipitated by a threat of revolution. The theory laid out in the present paper suggests that it would also be useful to look for evidence of situations where a revolutionary threat existed but no extension of the franchise occurred because the elite were able to defuse the threat using trade policy. To put this another way, the present paper provides a new motive for trade policy: to maintain political stability. And it provides a set of predictions about how this new motive could be tested for in the data.

The framework introduced in this paper focuses on a situation where world price shocks are permanent, which seems reasonable when the underlying forces driving the shocks are permanent such as technological innovation. Yet it seems likely that trade policy is also used to maintain political stability in response to temporary world price shocks as well. The model developed in this paper could be extended to consider other situations where world price shocks are temporary, 
such as crop failures arising from extreme weather events. For example between 2007 and 2011, in response to a large but temporary spike in world food prices, an estimated 33 food-exporting countries resorted to restrictions on exports of grains, rice, and other foodstuffs in response to the initial increase in food prices (Sharma 2011). Moreover, a number of these countries were dictatorships such as Egypt and Jordan. Burke and Leigh (2010) find no evidence that temporary terms-of-trade shocks driven by demand side factors precipitated democratic transitions. Seen in the light of the theory developed in the present paper, their findings provoke the question of whether the threat of revolution was defused using trade policy. This issue could be explored theoretically by combining the model of temporary surges in import demand developed by Bagwell and Staiger (2003) with the one developed in the present paper.

Second, what does the framework tell us not just about how dictatorships respond to price shocks but how democracies respond as well? After all, in the recent food price shocks, although some of the countries that restricted exports were dictatorships some were democracies. We can get an idea of how the model could be extended to consider the trade policy reaction of a democratically elected government by looking at equilibrium equation (18). In a democracy the costs of losing power are likely to be smaller and shorter lived. The overall time horizon over which the costs of losing power must be discounted might also be shorter, say the normal expected life of a parliament. Having made these adjustments, maintaining the status quo using trade policy might nevertheless represent a reasonable way of thinking about the determination of policy in a democratic setting. To the extent that democracies have higher incomes they also tend to have greater fiscal capacity, implying greater reliance on domestic policy instruments to address such shocks and less reliance on trade policy. But since we sometimes observe similar trade policy responses in practice from some democracies, the model might offer some rudimentary insight into the forces at work.

Third, an empirical literature initiated by Goldberg and Maggi (1999) tests the predictions of the standard Grossman-Helpman type framework against the data. The present paper offers a framework that may do a better job of explaining the patterns in the data under dictatorship. The testable predictions seem quite straightforward. If a ruling elite own a scarce factor then democratization and trade liberalization will be positively related. If they own an abundant factor then the relationship will be negative. My sense is that, before this model can be tested econometrically, further research is needed to determine whether dictatorships and democracies 
can be considered within a unifying framework or whether they should be considered separately. But once we have a clearer idea of the answer to that question, the empirical testing of this framework offers an interesting agenda for future research.

Some of the ideas discussed above have been developed in a long-standing literature on trade policy as social protection. This literature has re-emerged recently to argue that while tradebased measures are second-best, they may represent the most practical redistributive policies available to many developing countries: see for example Do, Levchenko and Ravallion (2014) and the references therein. The present paper makes a different but related point that dictatorial regimes are unlikely to heed calls to remove export-restrictive measures if they are instrumental in their political survival. In future research it would be useful to try to distinguish empirically between these motivations for trade policy. One key difference between the two motivations is that the framework of the present paper envisages a relatively high level of asset inequality that would allow the elite to self-insure during times when world food prices move against them. On the other hand, social cohesion over a social insurance scheme would be more likely to arise in situations where the level of asset inequality were not so high. On this basis, it might be possible to use panel data on the land-gini as a way to distinguish between the motivation for export restrictions during food price shocks. Another aspect is that the higher levels of social cohesion associated with the operation of social insurance schemes are more closely associated with democracy than dictatorship. This is consistent with the fact that the social insurance literature assumes that the government will operate the scheme for sure, perhaps under the assumption that it is bound by a democratic mandate. The approach to policy assumed in the present paper is that the government would only operate such a scheme when it was forced to do so; motivation more closely associated with dictatorship. Therefore, in attempting to distinguish between these motivations, it might be possible to use the form of government as a determinant. Much work remains to be done in order to fully understand the use of trade policy to maintain political stability proposed in the present paper, and how important this motivation for trade policy is compared to others. 


\section{References}

[1] Acemoglu, D., S. Johnson, and J. A. Robinson, (2001); "The Colonial Origins of Comparative Development: An Empirical Investigation." American Economic Review, 91(5): 1369-1401.

[2] Acemoglu, D., and J.A. Robinson, (2000); "Why Did the West Extend the Franchise? Democracy, Inequality and Growth in Historical Perspective." Quarterly Journal of Economics, 115: 1167-1199.

[3] Acemoglu, D., and J.A. Robinson, (2001); "A Theory of Political Transitions." American Economic Review, 91(4): 938-963.

[4] Acemoglu, D., and J.A. Robinson, (2006); Economic Origins of Dictatorship and Democracy, Cambridge University Press, New York, NY.

[5] Aidt, T.S., and M. Gassebner, (2010); “Do Autocratic States Trade Less?" World Bank Economic Review, 24(1): 38-76.

[6] Aidt, T.S., and P.S. Jensen, (2009); "Tax Structure, Size of Government and the Extension of the Voting Franchise in Western Europe, 1860-1938." International Tax and Public Finance, 16: 160-175.

[7] Aidt, T.S., and P.S. Jensen, (2014); "Workers of the World, Unite! Franchise Extension and the Threat of Revolution in Europe, 1820-1938." European Economic Review 72: 52-75.

[8] Bagwell, K., and R. Staiger, (1990); "A Theory of Managed Trade." American Economic Review, 80, 779-795.

[9] Bagwell, K., and R. Staiger, (1999); "An Economic Theory of the GATT." American Economic Review, 89(1): 215-48.

[10] Bagwell, K. and R. Staiger, (2003); "Protection and the Business Cycle." Advances in Economic Analysis \& Policy, Berkeley Electronic Press, 3(1), Article 3.

[11] Besley, T. and R. Jarayaman, (2010); "Introduction." Published in T. Besley and R. Jarayaman (eds.) Institutional Microeconomics of Development, MIT Press, Cambridge, Massachusetts, and London, UK.

[12] Besley, T., and T. Persson, (2011); Pillars of Prosperity: The Political Economics of Development Clusters, Princeton University Press, Princeton NJ. 
[13] Burke, P.J., and A. Leigh (2010); "Do Output Contractions Trigger Democratic Change?" American Economic Journal: Macroeconomics, 2(4): 124-157.

[14] Chipman, J., (1969); "Factor Price Equalization and the Stolper-Samuelson Theorem." International Economic Review, 10: 399-406.

[15] Chor, D., (2010); "Unpacking Sources of Comparative Advantage: A Quantitative Approach." Journal of International Economics, 82(2): 152-167.

[16] Collier, P., (1999); "On the Economic Consequences of Civil War." Oxford Economic Papers, 51(1): 168-183.

[17] Costinot, A., (2009); "On the Origins of Comparative Advantage." Journal of International Economics, 77: 255-264.

[18] Decker, J., and J. Lim, (2009); "Democracy and Trade: An Empirical Study." Economics of Governance, 10(2): 165-186.

[19] Do, Q.-T., A.A. Levchenko, and M. Ravallion, (2014); "Trade Insulation as Social Protection." Published in J.-P. Chavas, D. Hummels, and B. Wright (eds) The Economics of Food Price Volatility, NBER and University of Chicago Press. Also World Bank Policy Research Working Paper 6448.

[20] Engerman, S.L., and K.L. Sokoloff, (1997); "Factor Endowments, Institutions, and Differential Paths of Growth Among New World Economies: A View from Economic Historians of the United States." Published in S. Harber How Latin America Fell Behind, Stanford University Press, Stanford.

[21] Farrell, S., (2010); "A First Step Towards Democracy." History Today, 60: 10-17.

[22] Galiani, S., and G. Torrens, (2014); "Autocracy, Democracy and Trade Policy." Journal of International Economics, 93(1): 173-193.

[23] Garfinkel, M., S. Skaperdas, and C. Syropoulos, (2008); "Globalization and Domestic Conflict." Journal of International Economics, 76(2): 296-308.

[24] Garrett, G., (2000); "The Causes of Globalization." Comparative Political Studies 33(6-7): 941-91.

[25] Goldberg, P.K., and G. Maggi, (1999); "Protection for Sale: An Empirical Investigation." American Economic Review, 89(5): 1135-1155. 
[26] Grossman, G., and E. Helpman, (1994): "Protection for Sale." American Economic Review 84(4): 833-850.

[27] Hillman, A.L., (1982); "Declining Industries and Political-Support Protectionist Motives." American Economic Review, 72(5): 1180-87.

[28] Hillman, A.L., and H.W. Ursprung, (1988); "Domestic Politics, Foreign Interests, and International Trade Policy." American Economic Review, 78(4): 729-45.

[29] Jack, W., and R. Lagunoff, (2006); "Dynamic Enfranchisement." Journal of Public Economics, 90(4-5): 551-572.

[30] Jones, R.W., (1965); "The Structure of Simple General Equilibrium Models." Journal of Political Economy, 73(6): 557-72.

[31] Kindleberger, C.P., (1975); "The Rise of Free Trade in Western Europe, 1820-1875." Journal of Economic History, 35(1): 20-55.

[32] La Porta, R., F. Lopez-de-Silanes, A. Shleifer and R.W. Vishny, (1997); "Legal Determinants of External Finance." Journal of Finance, 52(3): 1131-50.

[33] Levchenko, A.A., (2007); "Institutional Quality and International Trade." Review of Economic Studies, 74:3 (July 2007), 791-819.

[34] Levchenko, A.A., (2013); "International Trade and Institutional Change." Journal of Law, Economics, and Organization, 29(5): 1145-1181.

[35] Liu, X., and E. Ornelas, (2014); "Free Trade Agreements and the Consolidation of Democracy." American Economic Journal: Macroeconomics, 6(2): 29-70.

[36] Lizzeri, A., and N. Persico, (2004); "Why Did the Elites Extend the Suffrage? Democracy and the Scope of Government, with an Application to Britain's Age of Reform." Quarterly Journal of Economics, 119(2): 705-763.

[37] Llavador, H., and R.J. Oxoby (2005); "Partisan Competition, Growth, and the Franchise." Quarterly Journal of Economics, 120(3): 1155-1192.

[38] Maggi, G., and A. Rodríguez-Clare, (1998); "The Value of Trade Agreements in the Presence of Political Pressures." Journal of Political Economy, 106(3): 574-601. 
[39] Mayer, W., (1984); "Endogenous Tariff Formation." American Economic Review, 74(5): 970-985.

[40] North, D., (1981); Structure and Change in Economic History, Norton, New York.

[41] Nunn, N., (2007); "Relationship-Specificity, Incomplete Contracts, and the Pattern of Trade," Quarterly Journal of Economics, 122(2): 569-600.

[42] O'Rourke, K.H., and A.M. Taylor, (2007); "Democracy and Protectionism." Published in T.J. Hatton, K.H. O'Rourke and A.M. Taylor (eds) The New Comparative Economic History: Essays in Honor of Jeffrey G. Williamson, MIT Press, 193-216.

[43] O'Rourke, K.H., and J.G. Williamson, (1999); Globalization and History: The Evolution of a Nineteenth-Century Atlantic Economy. MIT Press, Cambridge, Massachusetts, and London, UK.

[44] Rodrik, D., (2007); One Economics, Many Recipes: Globalization, Institutions, and Economic Growth. Princeton University Press, Princeton NJ.

[45] Rogowski, R., (1989); Commerce and Coalitions: How Trade Affects Domestic Political Alignments. Princeton University Press, Princeton NJ.

[46] Schonhardt-Bailey, C., (2006); From the Corn Laws to Free Trade: Interests, Ideas, and Institutions in Historical Perspective. MIT Press, Cambridge, Massachusetts, and London, UK.

[47] Sharma, R., (2011); "Food Export Restrictions: Review of the 2007-2011 Experience and Considerations for Disciplining Restrictive Measures." FAO Commodity and Trade Policy Research Working Paper 32, Food and Agriculture Organization.

[48] Smith, A., (1776); An Enquiry into the Nature and Causes of the Wealth of Nations. Republished in 1977 by University of Chicago Press.

[49] Solar, P.M., (1997); "The Potato Famine in Europe." Published in C. O'Grada (ed. 1997) Famine 150: Commemorative Lecture Series. University College, Dublin.

[50] Syropoulos, C., (2002); "On Tariff Preferences and Delegation Decisions in Customs Unions: A Heckscher-Ohlin Approach." Economic Journal, 112(481): 625-648.

[51] Williamson, J.G., (2012); "Commodity Prices over Two Centuries: Trends, Volatility and Impact." Annual Review of Resource Economics 4: 6.1-6.22. 